\title{
Review of particle-in-cell modelling for the extraction region of large negative hydrogen ion sources for fusion
}

\author{
D. Wünderlich ${ }^{1)}$, S. Mochalskyy ${ }^{1)}$, I. M. Montellano ${ }^{1)}$, A. Revel $^{2)}$ \\ ${ }^{1}$ Max-Planck-Institut für Plasmaphysik, Garching, Germany \\ ${ }^{2}$ Laboratorire de Physique des Gaz et des Plasmas, CNRS, University Paris-Sud \\ Corresponding author: D. Wünderlich, e-mail address: dirk.wuenderlich@ipp.mpg.de
}

\begin{abstract}
Particle-in-cell (PIC) codes are used since the early 1960s for calculating self-consistently the motion of charged particles in plasmas, taking into account external electric and magnetic fields as well as the fields created by the particles itself. Due to the used very small time steps (in the order of the inverse plasma frequency) and mesh size the computational requirements can be very high and they drastically increase with increasing plasma density and size of the calculation domain. Thus, usually small computational domains and/or reduced dimensionality are used. In the last years the available CPU power strongly increased. Together with a massive parallelization of the codes it is now possible to describe in 3D the extraction of charged particles from a plasma, using calculation domains with an edge length of several centimeters, consisting of one extraction aperture, the plasma in direct vicinity of the aperture and a part of the extraction system.

Large negative hydrogen or deuterium ion sources are essential parts of the neutral beam injection (NBI) system in future fusion devices like the international experiment ITER and the demonstration reactor DEMO. For ITER NBI RF driven sources with a source area of $0.9 \times 1.9 \mathrm{~m}^{2}$ and 1280 extraction apertures will be used. Extraction of negative ions is accompanied by co-extraction of electrons which are deflected onto an electron dump. Typically, the maximum negative extracted ion current is limited by the amount and the temporal instability of the co-extracted electrons, especially for operation in deuterium. Different PIC codes are available for the extraction region of large driven negative ion sources for fusion. Additionally, some effort is ongoing in developing codes that describe in a simplified manner (coarser mesh or reduced dimensionality) the plasma of the whole ion source.

The presentation first gives a brief overview of the current status of the ion source development for ITER NBI and of the PIC method. Different PIC codes for the extraction region are introduced as well as the coupling to codes describing the whole source (PIC codes or fluid codes). Presented and discussed are different physical and numerical aspects of applying PIC codes to negative hydrogen ion sources for fusion as well as selected code results. Main focus of future calculations will be the meniscus formation and identifying measures for reducing the co-extracted electrons, in particular for deuterium operation. Recent results of the 3D PIC code ONIX (calculation domain: one extraction aperture and its vicinity) for the ITER prototype source (1/8 size of the ITER NBI source) are presented.
\end{abstract}

\section{INTRODUCTION}

Aim of this paper is to give an overview of the current status of Particle-in-Cell (PIC) codes for the extraction region of large negative hydrogen ion sources for fusion. The paper splits up in three parts: i) the introduction motivates the application of negative hydrogen ion sources for fusion and summarizes the main issues and the current status, focused on the RF driven sources for neutral beam injection (NBI) at the international fusion experiment ITER. Additionally, the PIC method is introduced. ii) The second section introduces different PIC codes available for the extraction region of negative hydrogen ion sources for fusion, gives an overview of different physical and numerical aspects of applying such codes and presents selected results. iii) The third and final section focuses on the 3D PIC code ONIX, being applied to the RF driven ITER prototype ion source and the half-ITERsize ion source of the ELISE test facility. The current status of the code and current results are presented. 
The ion sources are operated in hydrogen or deuterium. ITER will finally be operated with deuterium and tritium and thus the NBI has to be based on negative deuterium ions. However, most theoretical investigations performed up to now have been done for hydrogen only. For the sake of simplicity, throughout the paper the term 'hydrogen' means either hydrogen or deuterium, unless otherwise specifically mentioned

\section{Negative hydrogen ion sources for fusion}

Neutral beam injection (NBI) systems based on the production, extraction, acceleration and neutralization of negative hydrogen ions are used at the Stellarator experiment LHD [1] at NIFS, have been used at the Tokamak JT$60 \mathrm{U}$ [2] at JAEA, currently being upgraded to JT60-SA [3] and are foreseen for the international Tokamak project ITER $[4,5]$. Since the working principle of the different used negative hydrogen ion sources is in principle similar, the following description of the experiment will focus on the ion sources for ITER. The overview on the different available PIC codes, however, will consider codes applied to all these ion sources and/or the respective test facilities.

For ITER, two NBI systems with $33 \mathrm{MW}$ total power at a beam energy of $1 \mathrm{MeV}$ are foreseen. In order to deliver these parameters, a large area (width: $0.9 \mathrm{~m}$, height: $1.9 \mathrm{~m}$ ) negative hydrogen ion source is necessary, capable of delivering an extracted current of $57 \mathrm{~A}$ for $3600 \mathrm{~s}$ in deuterium operation and $66 \mathrm{~A}$ for $1000 \mathrm{~s}$ in hydrogen (corresponding to current densities of $28.5 \mathrm{~mA} / \mathrm{cm}^{2}$ and $33.0 \mathrm{~mA} / \mathrm{cm}^{2}$, respectively).

In order to minimize stripping losses of negative ions in the accelerator, the source has to be operated at a filling pressure of $0.3 \mathrm{~Pa}$. Additionally, to limit the power loads in the extraction system, the co-extracted electron current has to be equal or smaller compared to the extracted negative ion current. For a good transmission the beam needs to have a homogeneity better than $90 \%$ with a divergence of better than $7 \mathrm{mrad}$.

Up to now, these parameters have not been achieved simultaneously. A stepwise development process for the neutral beam heating systems was defined by the European domestic agency F4E in a R\&D roadmap [6,7]. First step of this process is the RF driven negative ion source prototype (width: $0.3 \mathrm{~m}$, height: $0.6 \mathrm{~m}$ ) developed at IPP Garching [8,9], followed by the ELISE (Extraction from a large ion source experiment) test facility [10,11] with its half-ITER-size ion source (width: $0.9 \mathrm{~m}$, height: $1.0 \mathrm{~m}$ ). The ion sources used at the SPIDER and MITICA test facilities under construction at the neutral beam test facility PRIMA in Padova, Italy $[12,13]$ represent the final development step as they are in principal identical with the ion source of the ITER NBI system. A schematic view of the ELISE ion source is shown in figure 1.

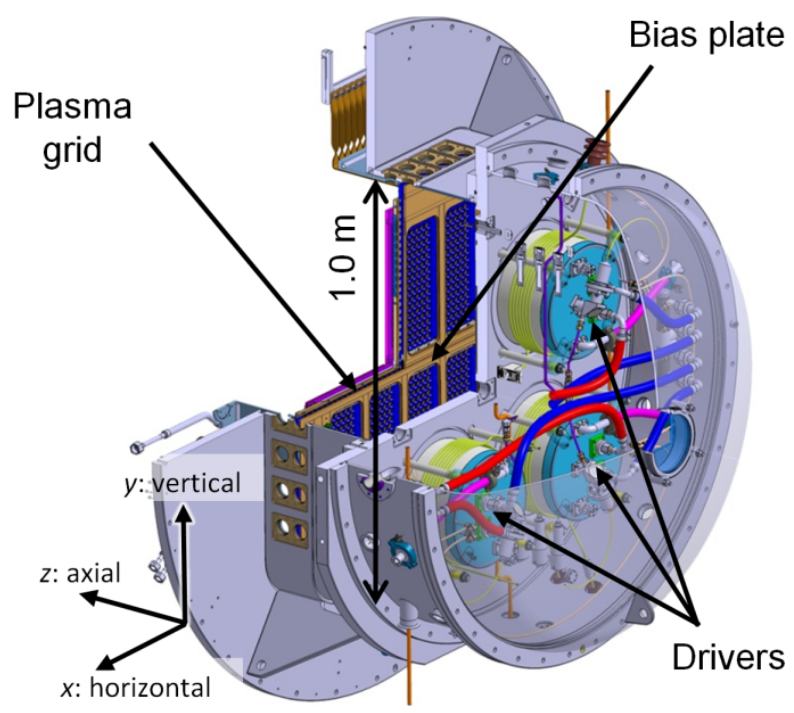

FIGURE 1. Schematic view of the ELISE ion source, together with the used coordinate system.

In these RF driven ion sources the plasma is generated in cylindrical drivers by inductive $\mathrm{RF}$ coupling $\left(P_{\mathrm{RF}}=\mathrm{up}\right.$ to $100 \mathrm{~kW} /$ driver, $f_{\mathrm{RF}}=1 \mathrm{MHz}$ ). The main advantage of the driver concept is the modularity, which enables the extension to large sources by adding several drivers to one common expansion chamber. While the prototype source 
is based on one single driver, the ELISE source uses four drivers, powered by two RF generators (each generator powers to two neighboring drivers which are connected in series) and the ITER source uses eight drivers.

Negative ions are produced predominantly $[14,15]$ via the surface conversion process [16] of neutral atoms on the surface of the first grid (plasma grid, PG, consisting of molybdenum-coated copper) of the multi-aperture extraction system. This process can be enhanced significantly (and favored over the volume process [16]) by evaporating caesium into the source and depositing it on the PG surface to reduce its work function. A caesium redistribution process, called caesium conditioning, is necessary in order to obtain a good source performance [17], i.e. a high extracted negative ion current and simultaneously a low current of co-extracted electrons. Starting from a clean source, i.e. without caesium, this caesium conditioning procedure can last up to several operational days.

A magnetic filter field in front of the PG ( $B_{\text {horizontal }}$ a few $\mathrm{mT}$, sufficient for magnetizing the electrons) is applied for minimizing the destruction of negative ions by electron collisions and for reducing the amount of co-extracted electrons. The magnetic filter field is generated in the prototype source by rods of permanent magnets, attached to the vertical side walls of the ion source [18]. In the ELISE source and the future ITER sources the filter field is generated by a current of several kA flowing in vertical direction through the PG [19].

A bias plate (BP), in principle an extension of the source walls, covers the part of the PG without extraction apertures. By applying a positive voltage (typically $\approx 20 \mathrm{~V}$ ) to the $P G$ with respect to the bias plate the plasma in front of PG can be influenced in a way that further reduces the current of co-extracted electrons [9].

In ELISE the extraction system consists of the PG, the extraction grid (EG) and the grounded grid (GG). The ITER system consists of the PG, the EG, four acceleration grids (AG) and the GG [20]. The apertures of the PG are chamfered in order to enhance the extraction probability for negative ions [8]. The diameter of the apertures is $14 \mathrm{~mm}$. In ELISE the superposition of 640 individual beamlets results in a beam of about $1 \mathrm{~m} \times 1 \mathrm{~m}$ while in the ITER system 1280 apertures create a beam of $1 \mathrm{~m} \times 2 \mathrm{~m}$. At ELISE the total available high voltage (up to $60 \mathrm{kV}$ ) is significantly smaller compared to the up to $1 \mathrm{MV}$ of ITER and beam divergences down to $1^{\circ}$ are obtained in perveance matched conditions.

The boundary between quasi-neutral plasma and the beamlets is called meniscus. The shape of the meniscus plays a crucial role for the quality (characterized mostly by the divergence) of the individual beamlets [21]. It is the result of the interplay of charged particle fluxes towards the extraction aperture, the geometry of the extraction system and the extraction potential [22].

Permanent magnets embedded into the EG generate the deflection field, bending the co-extracted electrons out of the beam at low energies and dumping them onto the surface of the EG. Depending on the caesium conditioning status and the source parameters the co-extracted electron current can show a pronounced increase during pulses [9]. It can also be strongly non-uniform between the top and bottom grid segment [23]. If the power deposited onto the EG is too high, beam extraction is stopped by a safety interlock. Thus, a high co-extracted electron current can prevent increasing the extraction voltage or the RF power in order to increase the extracted negative ion current. If the co-extracted electron current strongly increases during a pulse it can limit the length of the pulse. Typically, in deuterium plasmas the co-extracted electron current is larger and their temporal instability is more pronounced than in hydrogen [24]. The reason for these effects is currently not known.

The extraction region is the plasma volume close to the PG in that almost all physical aspects relevant for producing a uniform and stable negative hydrogen ion beam with a sufficiently low number of co-extracted electrons take place, including the formation of the meniscus. The interplay of different plasma drifts (mainly an $\mathbf{E} \times \mathbf{B}$ drift and a diamagnetic drift $[25,26])$ can result in a strong three-dimensional character of the plasma in the extraction region. A typical value of the plasma density in this region is $10^{17} \mathrm{~m}^{-3}$.

Dedicated caesium distribution techniques [27], modifying the filter field topology [28] and inserting vertical potential rods [29] resulted in a remarkable progress towards fulfilling at ELISE the physical ITER requirements [9]. Extracted current densities of $30.4 \mathrm{~mA} / \mathrm{cm}^{2}$ (hydrogen) and $25.0 \mathrm{~mA} / \mathrm{cm}^{2}$ (deuterium) have been demonstrated for short pulses (20 s plasma with $10 \mathrm{~s}$ beam). During long pulses densities of $21.8 \mathrm{~mA} / \mathrm{cm}^{2}$ (hydrogen, $1160 \mathrm{~s}$ plasma) and $19.1 \mathrm{~mA} / \mathrm{cm}^{2}$ (deuterium, $2740 \mathrm{~s}$ plasma) have been obtained using pulsed extraction $(10 \mathrm{~s}$ beam each $180 \mathrm{~s}$ ). The limitation for a further increase of the ion current is given by the amount and temporal stability of the coextracted electron current. These effects are closely linked to the caesium re-distribution inside the source.

Final aim should be to modify the caesium re-distribution in a way that ensures a stable low PG work function for one hour pulses with high $P_{\mathrm{RF}}$, i.e. for a high extracted negative ion current. Application of computational models can be extremely useful in this context: models allow predicting the effect of parameter changes in a wide range and investigating basic physical effects not accessible by diagnostics. Additionally, models seem to be the only approach towards understanding the reason for the strong observed isotope effect between hydrogen and 
deuterium. Another open question to be answered by models is if the currently used design of the PG can be further optimized in order to increase the extracted ion current.

Due to their self-consistent character, PIC codes may be the appropriate tool for opening the door to answering these still open questions in operating large negative hydrogen ion sources for fusion.

\section{Particle in Cell models}

Particle-in-Cell (PIC) models self-consistently calculate the trajectories of individual charged particles and the spatial density distributions of different charged particle species in plasmas [30,31,32]. Taken into account are external magnetic and electrostatic fields as well as the fields generated by the plasma particles themselves.

Starting with a set of initial conditions (geometry, particle positions, particle velocities) PIC codes track the trajectories of individual charged particles over a certain period of time, divided in small time steps $\Delta t$. Typically macroparticles, consisting of up to several thousands of real particles, are used. The charge to mass ratio of these macroparticles is identical to the one of real particles and their trajectories, described by the Lorentz force, are identical to the trajectories of real particles.

The history of PIC codes started in the late 1950s and early 1960s. In the first codes the electrostatic forces between the charged particles were calculated by solving the Coulomb equation for each particle [33], resulting in a computational effort of $N^{2}$ with $N$ the number of macroparticles. The breakthrough came when a computational grid was introduced, resulting in a drastic reduction of the computational effort. This grid is typically based on either the finite difference method (FDM) or the finite element method (FEM).

For each time step the following procedure is done: the charge of the macroparticles is projected onto the grid nodes and the following steps are performed on the grid knots: i) solve Poisson's equation in order to obtain the electrostatic potential and ii) determine the electric field by differentiating the potential (and adding externally applied fields). Finally, the electric field is projected back onto the positions of the individual macroparticles.

The calculated electric field then is used for calculating a new velocity and position of the macroparticles. This can be done by using either explicit [30] or implicit [34,35] methods. Explicit methods use the particle position and velocity from the previous time step and update them using the calculated electric field. Such methods are very simple and fast but the time step has to be smaller than for implicit methods. Widely used explicit schemes for implicit PIC codes are the leapfrog [30] method and the Boris scheme [36]. The latter conserves the volume of the phase space and thus is has excellent long term accuracy. In implicit methods determining the electric field of a time step requires pre-knowledge of the new particle positions and velocities and vice versa. Solving this problem exactly would be too time-consuming and usually approximate methods, for example based on a Taylor expansion are used. Implicit methods have the advantage of allowing larger time steps but they are significantly more complex to implement.

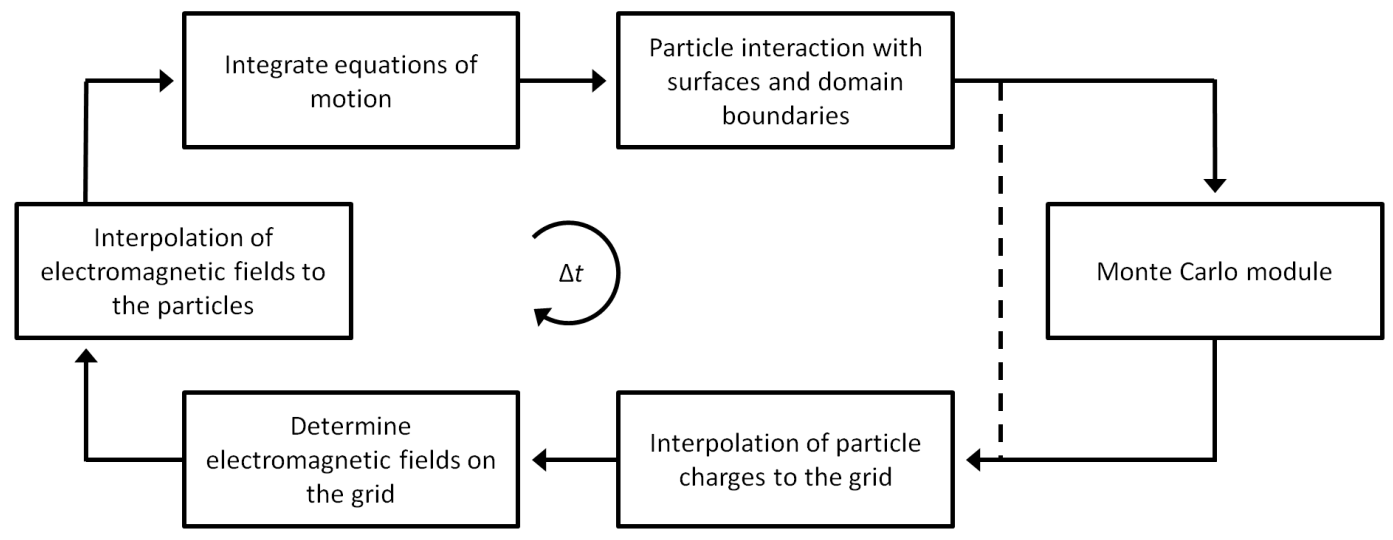

FIGURE 2. Basic solution scheme of PIC codes.

After the new positions of the macroparticles have been calculated, it is checked if macroparticles did collide with a surface or left the calculation domain. In case of surface collisions the code takes the appropriate action, e.g. reflect the particle at the wall or produce a secondary particle or change the charge of the surface. The boundaries of 
the calculation domain can represent either a surface or the transition to a larger plasma volume. In the first case leaving the domain is treated like a surface collision. In the second case the macroparticle is either removed from the calculation or - in the case of periodic boundary conditions [30] - re-injected at the opposite domain boundary. If necessary, the velocity of the macroparticle is adjusted before re-injection.

Collisions processes (Coulomb collisions, elastic or inelastic collisions) can be implemented by dedicated Monte Carlo (MC) modules. A widely used method for treating Coulomb collisions is the binary collision method [37,38] where particles in the individual cells of the computational grid are randomly paired and then collided. The treatment of elastic or inelastic collisions can be significantly accelerated by the null collision method [39], introducing a virtual collision process resulting in a total collision cross section that is constant over the (relative) particle energy. In order to model complex plasma chemistry, is not unusual to couple PIC-MC codes with MC codes for the neutral particles in the plasma.

The described procedure is repeated until stable conditions have been reached. The solution scheme is illustrated in figure 2.

As one prerequisite for producing stable and accurate results, PIC codes have to fulfill several conditions, mainly regarding the size of the time steps and the grid cells. Both have to be chosen in a way that the time and length scale phenomena of interest are resolved: i) $\Delta t<0.2 \omega_{\mathrm{p}}^{-1}$ where $\omega_{\mathrm{p}}$ is the plasma frequency [40]. ii) In order to avoid grid instabilities that can result in numerical heating of the particles, usually the grid cell size $\Delta x$ is chosen to be similar to or smaller than the Debye length $\lambda_{\mathrm{D}}$ [40]. Numerical investigations show that depending on the specific application case numerically stable results can also be obtained using cells larger than $\lambda_{\mathrm{D}}$ and that the maximum possible grid cell size depends on the scheme used for particle and field projection onto and from the computational grid $[41,42]$. In [43] it has been demonstrated empirically that using grid calls up to three times larger than $\lambda_{\mathrm{D}}$ can result in stable results if time steps significantly smaller than $\omega_{\mathrm{p}}{ }^{-1}$ are used. It has to be kept in mind that even if a PIC code is numerically stable, effects taking place on length scales smaller than $\Delta x$ are neglected. iii) $\Delta t<\Delta x / v_{\max }$ where $v_{\max }$ is the velocity of the fastest macroparticle. This criterion is called Courant-Friedrichs-Lewy condition $[44,30]$. iv) The number of macroparticles in each of the cells of the computational grid has to be sufficiently high in order to result in a low temporal oscillation of the electromagnetic field generated be these particles. Although this rule cannot be expressed by a specific formula it can be stated that the local amplitude of oscillations is proportional to $1 / \sqrt{N}$ with $N$ being the number of macroparticles present in a specific grid cell.

Since implicit methods allow using larger time steps, larger grid cells are possible without violating the CourantFriedrichs-Lewy condition. This in turn results in a smaller number of macroparticles necessary for obtaining small field oscillations. Overall, the required computational effort can be significantly reduced by using PIC codes based on implicit methods.

The main advantage of PIC codes over other computational methods is their self-consistent character regarding for example the magnetic and electrostatic fields generated by the plasma particles and the energy distribution functions of the modelled particle species. Their main disadvantage is the high needed computational effort. In order to reduce this effort the calculation domain of PIC codes often is restricted to small plasma volumes and reduced plasma densities are used. Often, PIC codes are parallelized; some PIC codes also exploit the strongly parallel character of Graphic Processing Units (GPU).

\section{PARTICLE IN CELL MODELLING OF NEGATIVE ION SOURCES FOR FUSION}

Due to the complex 3D structure of the electric and magnetic fields in large negative ion sources for fusion, desirable are PIC codes reproducing the full ion source in 3D. Even using the largest available supercomputers such codes are not even in sight when fulfilling the stability rules regarding the time step and the grid cell size.

The application of PIC codes to such ion sources started using 1D [45,46] and 2D [47,48] models on reduced computational domains describing a small plasma volume in the extraction region close to one extraction aperture. At this time also first 3D calculations have been performed but using grid cells much larger than the Debye length $[49,50]$. However, these 3D investigations were the very first calculations modeling the circular shape of the extraction aperture (as a matter of principle in 2D the aperture is approximated by a slit and in 1D by a point).

Since then, the increasing available computational resources and parallelization of the codes enabled increasing both the dimensionality and the size of the calculation domain. Currently, mainly 2D, 2.5D and 3D codes are used. However, most of these codes still are restricted to reduced computational domains. Some also use reduced plasma parameters (e.g. a reduced plasma density) or scaled physical constants (e.g. an increased vacuum permittivity $\varepsilon_{0}$ ) in order to allow using larger grid cells and thus reduce the computational effort. 
The applied reduced calculation domain typically has an edge length of a few $\mathrm{cm}$ and it consists of the plasma region in close vicinity of one extraction aperture (in the PG), the aperture itself (i.e. including the meniscus) and some part of the extraction system. Reducing the domain mainly implies issues regarding the coupling of the computational domain to the bulk plasma (see below). Scaling plasma parameters or physical constants may imply the necessity of scaling other parameters and/or properties of the ion source. If the latter is not done appropriately, scaling can result in a reduced applicability of code results to the experiment.

At present, different 2D codes are available: the code package of Keio University, Japan [51,52], using a reduced domain, has been lastly applied for investigating the formation of the meniscus. Available at CNR-Nanotec, Bari, Italy is a 2.5D PIC model simulating (using a scaled value of $\varepsilon_{0}$ ) the full region between the driver exit plane of the RF driven prototype source to the entrance of the EG [53]. At LAPLACE, Université de Toulouse, 2D and 2.5D codes are applied for basic investigations [54,55], using a reduced domain or the full ITER prototype source as domain; in both cases the plasma density is strongly reduced.

Four different groups are working on 3D codes with reduced domains: the code developed at Keio University, Japan ("Keio-BFX") is applied mainly for investigating the formation of the ion-ion plasma [56] close to the extraction system as well as for investigations on the meniscus formation [57,58]. The 3D code by CNR-Nanotec, Bari, Italy ("Bari-Ex"), has been lately applied [59] for modelling the extraction system of the small ion source test bed NIO1 [60,61]. At LAPLACE, Université de Toulouse, a 3D PIC code is applied for modeling the plasma transport in RF driven negative ion sources [55]. These calculations are again based on a strongly reduced value of the plasma density. The ONIX code $[62,63]$ has been initially developed at LPGP, Université Paris, France and is now being advanced in close cooperation by LPGP and IPP Garching in order to investigate the formation of the meniscus and mechanisms responsible for the co-extraction of electrons from the RF driven prototype source and the ELISE source and the isotope effect hydrogen-deuterium.

In the following a brief overview is given on different physical and numerical aspects of applying PIC codes to negative hydrogen ion sources for fusion as well as on selected code results.

\section{Validation of the codes}

Validation of PIC codes should be done - if possible - against general physical laws, other codes and experimental results. General physical laws that can be used are the dependence of the depth and the width of the plasma sheath on the electron temperature and the electron density. Simple equations for these properties exist $[64,65]$ for electropositive plasmas (consisting only of electrons and positive ions) in the collisionless case, without external electric or magnetic fields. Comparing as first validation step calculation results for such plasma conditions with the theory is mandatory for each PIC code. As next step, the surface production of electrons can be added and the impact of the additional electrons on the sheath depth can be compared with the theory [66,64]. The full validation procedure is described in detail for ONIX in [67]. Two of the results are shown in figures $3 \mathrm{a}$ and $3 \mathrm{~b}$, comparing the dependence of the sheath depth and width on the electron temperature and the electron density, respectively, from ONIX with results of the 1D PIC code used in [46], the result of a simple analytic model based on [68] and the theoretical result from [64]. The latter is derived from a fluid model treatment of the ion flow. It has been demonstrated in [69] that different analytical approaches can produce slightly different results for the sheath depth vs. the electron temperature. The agreement between ONIX and the other results is very good.

A thorough code-to-code benchmark of three 3D codes (Keio-BFX, Bari-Ex and ONIX) has been initiated and is still ongoing [43]. First aim was to validate the basic modules of the codes (mainly particle and field projection onto and from the computational grid, Poisson solver). Two test cases have been finished up to now, comparing for the three codes: i) the potential profile for vacuum conditions (i.e. the solution of Laplace's equation). ii) for an electropositive plasma the potential profile and the extracted electron current density.

For vacuum conditions the agreement between the potential profiles calculated by the different codes is good; the discrepancies are below $5 \%$. For electron extraction from electropositive plasmas, however, larger discrepancies occur: the extracted electron current density estimated by the codes is between 350 and $420 \mathrm{~mA} / \mathrm{cm}^{2}$. The reason for this difference will be investigated in the future.

The last step of validating PIC codes is the comparison of code results with measured experimental values. Due to limited accessibility it is almost impossible to measure directly plasma parameters in the extraction region in close vicinity of the PG. Either indirect measurements have to be used or results of measurements taken in larger distance to the PG. For example, the shape of the meniscus is a very suited benchmark property since it reacts very sensitively on parameters like the fluxes of charged particles towards the aperture. It cannot be measured directly but 
the following indirect technique was proposed and applied in [70]: use the measured emittance (i.e. divergence vs. radius) of one individual beamlet as input for a backward calculation with a particle tracking code (like e.g. IBSimu [71] or Kobra3D [72]). In [70] the beamlet shape was measured using a CFC tile and an IR camera and the beamlet divergence was determined from the beamlet shape by applying an estimation procedure. Estimating the divergence in combination with performing a backward calculation procedure poses the risk of large error bars. An alternative procedure based on forward calculations (i.e. a parametric study) with a particle tracking code is in preparation at the CERN LINAC4 negative ion source $[73,74]$. Although first measurements of the beamlet emittance have been successfully done [75] with a slit-grid emittance meter, the accuracy of the measurements is still too low. It is planned to increase the accuracy of the measurements, e.g. by using an aperture-grid emittance meter.

An example for experimental results taken in some distance to the PG is the negative ion flow pattern measured in the NIFS negative ion source test facility in around $1.5 \mathrm{~cm}$ distance to the PG [76] that allows for a general comparison with negative ion trajectories from PIC codes.

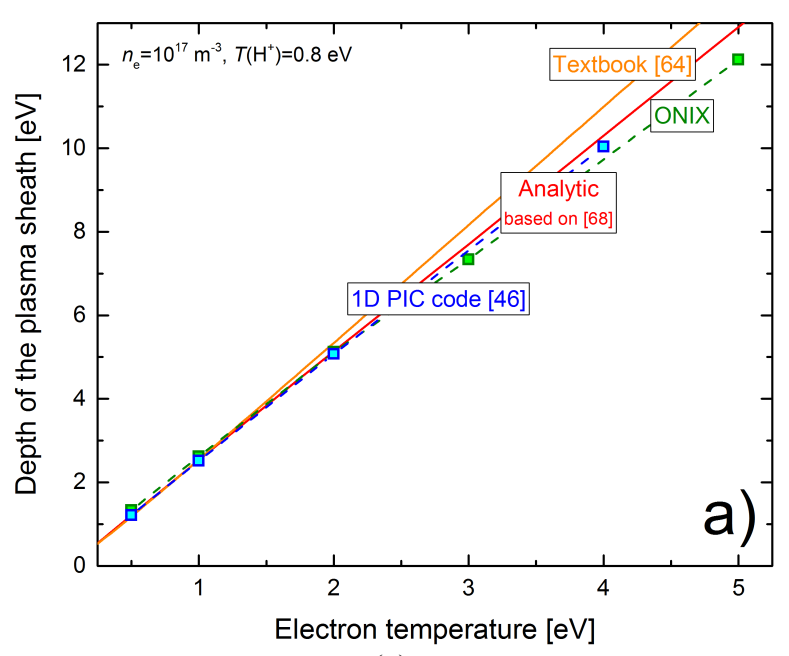

(a)

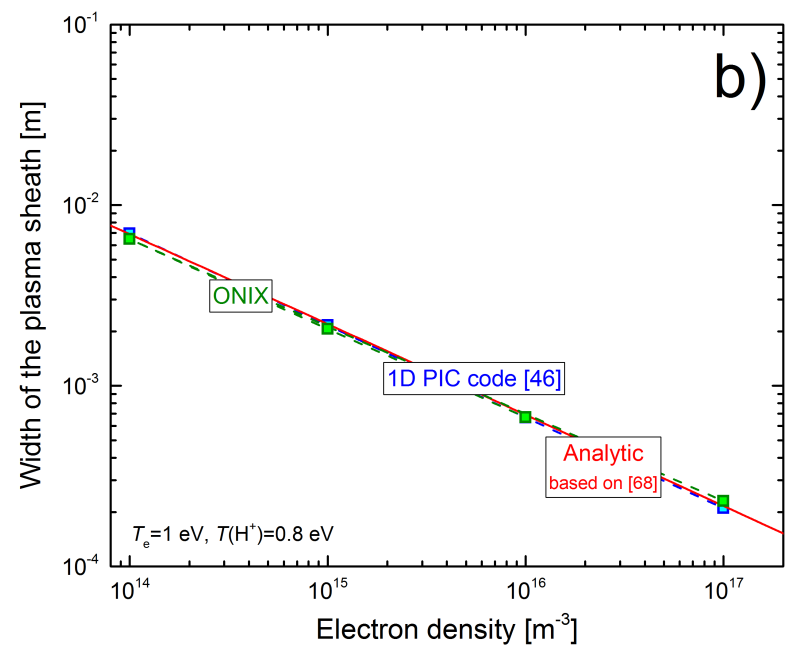

(b)

FIGURE 3. Successful benchmark of ONIX for an electropositive plasma. a) Depth of the plasma sheath vs. the electron temperature calculated by ONIX, a 1D PIC code, by a simple analytical model and the theoretical result from [64]. b) Width of the plasma sheath vs. the electron density from ONIX, a 1D PIC code and a simple analytical model.

It has to be kept in mind that most published PIC code results are based on calculation domains that include only the PG and the upstream surface of the EG, i.e. only the extraction of negative ions and the co-extraction of electrons from the plasma is treated but the acceleration of the ions is neglected. A comparison of code results with beamlet properties from the experiment - typically measured after full beam acceleration - is not feasible when such a short calculation domain is used. Instead of prolonging the calculation domain up to the last grid also coupling the PIC code to a second code for the transport of the beamlet particles is possible, as demonstrated in [58]. Due to the large Debye length in the beam and the high kinetic energy of the particles the second code can use much larger grid cells.

Concluding, in the last years significant progress has been made in benchmarking and validating the PIC codes against general physical laws and other codes. However, still a tremendous amount of work has to be done, especially regarding the continuation of the ongoing code-to-code benchmark and the benchmark vs. the experiment.

\section{Coupling to the bulk plasma}

As stated above, all current 3D PIC codes for negative hydrogen ions for fusion use a reduced calculation domain describing a small plasma volume close to one extraction aperture. Correct coupling of this reduced domain to the bulk plasma (i.e. the plasma volume between the driver exit plane and the domain) is mandatory, both in a numerical and a physical sense. 


\section{Numerical aspects}

The best possible approach for modeling the plasma flux into the reduced domain is injecting fluxes of charged particles at the transition between the bulk plasma and the domain, i.e. at the domain edge, using flux velocity distribution functions [77] for the injected particle species. The different velocities of injected positive and negative species can result in the formation of a plasma sheath at the location of injection, the source sheath $\left(\Delta \phi_{\text {source }} \approx 0.5 \cdot T_{\mathrm{e}}\right)$ [68]. Numerical techniques are available to mitigate the source sheath [78].

While some 1D [46] and 2D codes [47,48] applied for negative ion sources for fusion use particle injection at the domain edge, all current 2D and 3D codes use an injection volume inside the calculation domain. Particles are injected into the injection volume each time step with fixed injection rates and/or are re-injected when they are lost by hitting a wall. Most widely used is the re-injection scheme where a positive ion being lost at a wall results in the re-injection of an electron and a positive ion. If a different re-injection scheme is to be used, a critical validation is mandatory in order to avoid non-physical results [54,63]. Using an injection volume and re-injecting lost particles reduces the needed computational time and additionally has the advantage of being relatively easy and intuitive to implement. The different loss times of fast and slow particles from the injection volume can result in non-physical effects like heating or cooling that has to be counteracted by appropriate measures, e.g. an artificial thermalization process $[79,63]$.

In both cases (injection at the domain edge and using an injection volume) Neumann boundary conditions for the potential (typically $\delta \phi / \delta x=0$ ) best represent the transition from the domain to the bulk plasma. The reason is that usually the edge of the calculation domain is located in a plasma volume with flat electrostatic potential. Using nonrealistic potential profiles can result in a too high or too low loss of charged particles from the domain and consequently too high or too low particle densities in the calculation domain. Additionally, the spatial distance has to be sufficiently large between particle injection and the region in which relevant physical effects take place. For example, the transport of electrons from a field free region into the magnetic filter cannot be simulated correctly when the electrons are (re)-injected directly into the filter.

\section{Physical aspects}

Since a full PIC model of the whole ion source is not in reach, a more complete modelling approach could be based on the following two-step approach: i) Apply a global code for obtaining on a coarse spatial grid the particle densities and fluxes in the ion source. ii) Use these particle densities and fluxes as input for a PIC code using a reduced calculation domain and a fine grid.

The choice of a coarse grid in the first step implies that PIC codes are not the appropriate choice. Up to now, fluid codes are the best alternative. These models can do calculations on the scale of large negative ion sources for fusion, using realistic plasma parameters. The principal disadvantages of fluid codes compared to PIC codes (e.g. the particle energy distribution functions are not self-consistent results of the model but necessary input parameters) do not pose an issue. Up to now no 3D fluid model exists for these ion sources. Efforts have been done some while ago at Université de Toulouse to establish 2D models for the prototype source [80,81]. The most recent fluid model approach is in 2D and available for the prototype source and the ELISE source [26,82], taking into account the different filter field topologies of the two test facilities. The profiles shown in figure $4 \mathrm{a}$ were calculated using this model. The fluid model self-consistently determines the RF coupling into the plasma and treats the losses of particles along the magnetic field lines. A coupling of this 2D fluid code to ONIX is planned, based on the procedure described above.

Recently, some efforts have been done to describe the global behavior of the ion source plasma also with 2.5D PIC codes [53,55]. These codes use a scaled value for the vacuum permittivity $\varepsilon_{0}$ (scaling factor 25) or a drastically reduced electron density (scaling factor 400), respectively. As mentioned above, such scaling may result in a reduced applicability of the code results to the experiment. Additionally, a 2D treatment is not sufficient for fully describing the $3 \mathrm{D}$ behavior of the plasma drifts. However, the results from these PIC codes may give in future additional insight in the behavior of the plasma of the extraction region.

Figure $4 \mathrm{a}$ shows a 2D profile of the electron density and electron flux (symbolized by arrows) calculated using the fluid code from $[26,82]$ for the ITER prototype source. Symbolized by the red box is the typical size of a reduced calculation domain used by 3D PIC codes. A schematic diagram of a reduced calculation domain, including one chamfered aperture of the PG and the meniscus, is shown in figure $4 \mathrm{~b}$. Up to now, 2D and 3D PIC codes based on such reduced domains use temporally constant and isotropic particle injection rates. The particle (re)-injection volume is indicated in figure $4 \mathrm{~b}$ by the orange box. Particles leaving the plasma in horizontal or vertical direction 
are re-injected using periodic boundary conditions [30], particles leaving the domain downstream the PG are removed.

As discussed in [53], this choice of particle injection and boundary conditions may not be always appropriate since it neglects important properties of the electron density and electron flow profile shown in Figure 4a: i) For small or large vertical coordinates (i.e. close to the side walls) the electron flux towards the PG is not perpendicular to the grid. ii) Close to the PG a wedge-shaped volume exists with increased electron density; this increased electron density is the result of the interplay of the different plasma drifts. Additionally, the choice of a reduced calculation domain and periodic boundary conditions - representing the sequential arrangement of an infinite number of apertures - is not capable of correctly describing effects taking place on length scales larger than the reduced domain. Examples are the production of negative hydrogen ions on the surface of the bias plate (the bias plate encompasses not individual apertures but groups of apertures [83]) and the changing strength of the magnetic filter field over the ion source $[18,19]$.

However, the standard approach should be OK for basic investigations and parameter dependency studies, for example on the co-extraction of electrons.
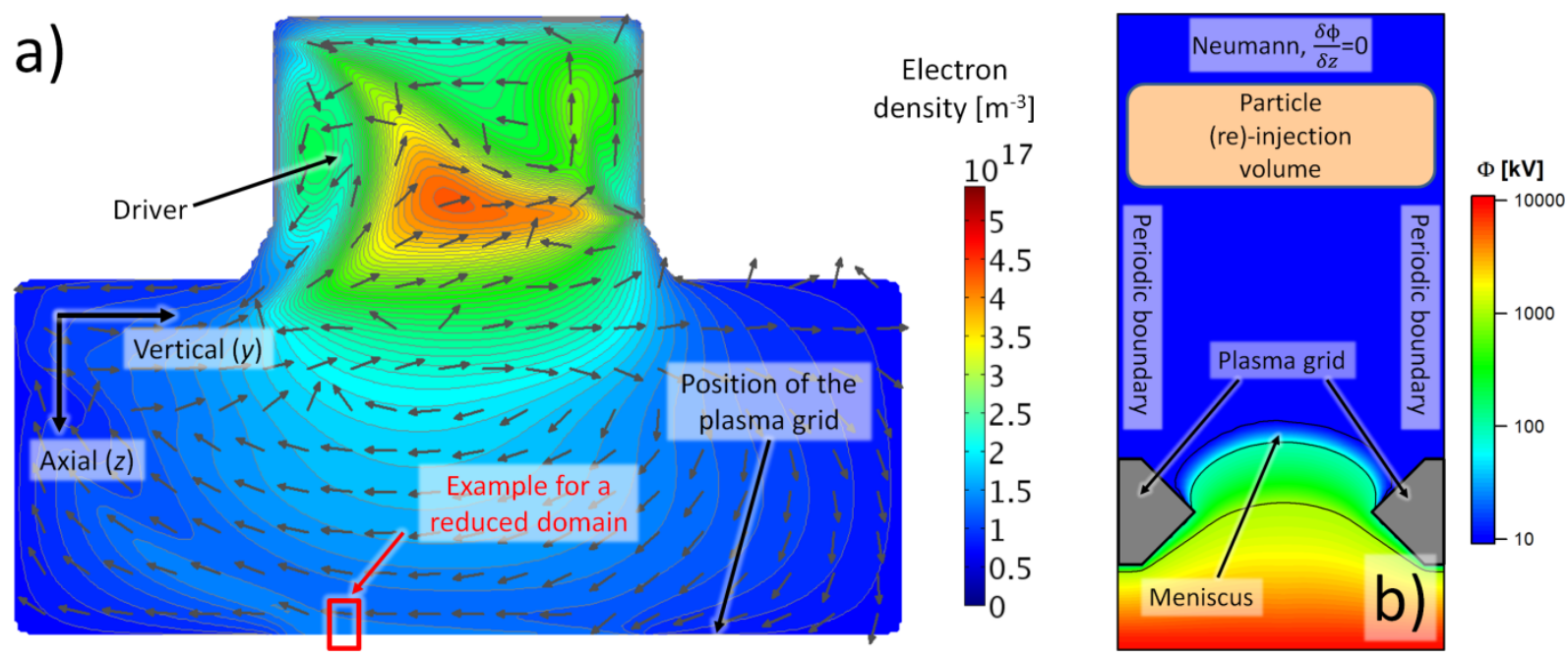

FIGURE 4. a) 2D profile of the electron density calculated for the ITER prototype source using a fluid code [26,82]. Symbolized by the red box is the size and position of a typical reduced calculation domain used by 3D PIC codes. Indicated by the arrows is the electron flux. b) Detailed view of the reduced domain with the particle (re)-injection volume, the boundary conditions and the meniscus.

\section{Virtual cathode}

The conversion of hydrogen atoms into negative ions at the PG surface adds a non-negligible amount of negative space charge into the plasma sheath. This situation is similar to the emission of secondary electrons, treated e.g. in $[66,64]$, where emission coefficients higher than a critical emission coefficient result in the formation of a virtual cathode: the space charge carried by the secondary electrons creates a potential well that reflects low energy secondaries back to the wall. The emission of secondary particles is space charge limited.

Using a 1D PIC code it was demonstrated that in negative hydrogen ion sources a similar virtual cathode can evolve [46]. For typical parameters of the ion sources $\left(n(\mathrm{H})=10^{19} \mathrm{~m}^{-3}\right.$, determining the atomic flux impinging the PG) and a well caesium conditioned PG surface the depth of the virtual cathode was determined to be about $0.5 \mathrm{eV}$, For $T\left(\mathrm{H}^{-}\right) \approx 0.6 \mathrm{eV}$ (using $T(\mathrm{H})=0.8 \mathrm{eV}[84]$ and the energy reflection coefficient of atoms at the metallic surface of the PG [85]) and an 1D Maxwell distribution function of the atoms, $54 \%$ of the surface produced ion have a kinetic energy smaller than $0.5 \mathrm{eV}$ and are reflected back to the surface. The density of negative hydrogen ions in the calculation domain $\left(\approx 10^{17} \mathrm{~m}^{-3}\right)$ and the electronegativity $\alpha$ of the plasma $\left(\alpha={ }^{n\left(\mathrm{H}^{-}\right)} / n_{\mathrm{e}} \approx 1\right)$ predicted by the code 
are in very good agreement with results of cavity-ringdown spectroscopy [86,17] and laser photodetachment [87], taken a few centimeters upstream the PG.

Figure 5a shows profiles of the $\mathrm{H}^{-}$density in the plasma for different values of the atomic density $n(\mathrm{H})$. The zero point in axial direction is the plasma facing surface of the PG. The atomic density is proportional to the rate of $\mathrm{H}^{-}$ generated by conversion of atoms. For atomic densities smaller than $10^{19} \mathrm{~m}^{-3}$ the negative ion density in the plasma increases with $n(\mathrm{H})$, for higher atomic densities the virtual cathode results in space charge limited transport of negative ions from the PG towards the plasma. Figure $5 \mathrm{~b}$ shows the dependence of the virtual cathode depth on the atomic density: for values of $n(\mathrm{H})$ higher than $10^{19} \mathrm{~m}^{-3}$ increasing the atomic density increases the depth of the virtual cathode.

Later, the existence of the virtual cathode was confirmed by 2D and 3D PIC codes $[88,89,54,56]$ and analytic investigations [90]. The depth of the virtual cathode predicted by PIC codes is correlated not only to the plasma parameters but also on how accurate the rules for the time step and the grid cell size are fulfilled by the code [54]. This is the most probable explanation for 3D code calculation results showing virtual cathodes with a depth of more than $20 \mathrm{~V}[89,91]$.

When the rules for the time step and the grid cell size are fulfilled, the structure of the virtual cathode and the emission of negative ions into the plasma depend on the dimensionality of the code and on how the plasma parameters or physical constants have been scaled: The 2.5D code used in [53] (calculation domain is the full region between the driver exit plane of the RF driven prototype source to the entrance of the EG, $\varepsilon_{0}$ is increased by a factor of 25) shows that the depth of the virtual cathode depends on the location at the PG surface: along the connection line between two adjacent apertures the depth reaches $1.5 \mathrm{~V}$ at the one side and it is absent on the other side. Nevertheless, the negative ion density in the plasma is too low compared to the experiment. In contrast, the 2.5D results presented in [55] (calculation domain is the full prototype source, electron density reduced by a factor of 400) show a depth of the virtual cathode of around $1 \mathrm{~V}$ but negative ion and electron densities around $10^{17} \mathrm{~m}^{-3}$ are observed in the vicinity of the PG.

All recent 3D calculations predict a cathode depth of about $1 \mathrm{~V}$ or higher $[54,63,67,56]$. For $T\left(\mathrm{H}^{-}\right)=0.6 \mathrm{eV}$ a virtual cathode depth of $1 \mathrm{eV}$ means that more than $80 \%$ of the negative ions are reflected back to the surface. Compared to the $1 \mathrm{D}$ code and to the measurements a significantly lower electronegativity is predicted for the plasma volume.

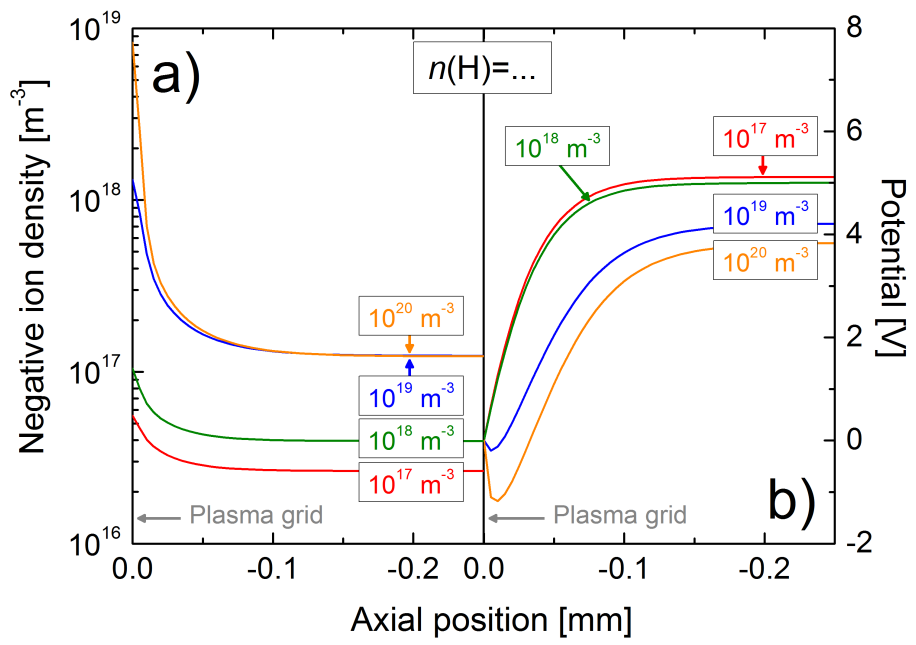

FIGURE 5. Formation of the virtual cathode close to the PG by surface produced negative hydrogen ions [46]. a) Profile of the $\mathrm{H}^{-}$density close to the PG surface for different values of the atomic density (negative ion conversion rate). b) Potential profile demonstrating the formation of the virtual cathode for high atomic densities.

Further reducing in the 3D models the depth of the virtual cathode may be possible by adding positive space charge; a promising candidate is the caesium ion. Caesium is ionized to a large degree in the experiment [92] but the $\mathrm{Cs}^{+}$ions are neglected in almost all current PIC code calculations. Investigations on this topic are ongoing.

Solving the described issues is a prerequisite for using 3D PIC codes for self-consistent investigations on the extraction of surface produced $\mathrm{H}^{-}$, as discussed in the following sections. 


\section{Transport of charged particles through the magnetic filter}

Understanding the mechanisms involved in the transport of charged particles through the magnetic filter is of essential importance in order to find measures stabilizing or even reducing the amount of co-extracted electrons, in particular when operating the sources in deuterium. The following two general statements describe the physical situation:

i) The coefficient for diffusion of the magnetized electrons perpendicular to the magnetic filter is small, resulting in a strongly reduced electron transport through the filter [93]. The electrons can move much faster parallel to the field lines than perpendicular to it. The fluxes of positive and negative particles impinging the wall do not have to compensate each other mutually on each point of the wall. The electrons may follow the magnetic field lines while the positive ions are not affected by the filter and continue their initial trajectories. Seen on a global scale, quasineutrality is still fulfilled. This effect is called Simon short circuit [94].

ii) Surface produced negative hydrogen ions with sufficient energy to overcome the virtual cathode are accelerated by the sheath into the plasma, resulting in an additional negative space charge. Usually it is assumed that these negative ions push back the much lighter electrons towards the direction of the bulk plasma. In the experiment, a high electronegativity of the plasma is measured a few centimeters upstream the PG $[87,17,76]$.

Theoretical considerations on the transport of charged particles through magnetic filters of negative ion sources have been done some while ago $[95,96,97]$, but only on 1D and not using a self-consistent model.

In [98] it was demonstrated using a PIC code that in 1D the transport of magnetized electrons through a transverse magnetic filter is governed purely by collisions and thus the electron density is strongly reduced by the filter. The collision process most relevant for the electron transport in the filter is elastic collisions. Due to the low perpendicular diffusion coefficient the residence time of the electrons inside the filter is high. Electron cooling occurs by a combination of electron-ion coulomb collisions (the collision frequency of this process increases for low electron velocities [99] and the favored transport of slow electrons results in an effective electron cooling) and sudden energy loss caused by inelastic collisions.

Similar results were obtained using a 1D code in [100] but in this publication also results of a 2D code with a small calculation domain and periodic boundary conditions were presented. The $2 \mathrm{D}$ code results indicate that in the magnetic filter temporal instabilities are likely to occur and that these instabilities may play a role in the transport of electrons through the magnetic filter. The same authors published results of a 2D code for the full prototype source, using a strong scaling of the plasma density [25]. These results demonstrate, in agreement with the fluid code results discussed above, the strong role of different plasma drifts for the electron transport through the magnetic filter. In principle comparable results have been presented later using a 2.5D code for the full source [53], using a scaled value of $\varepsilon_{0}$.
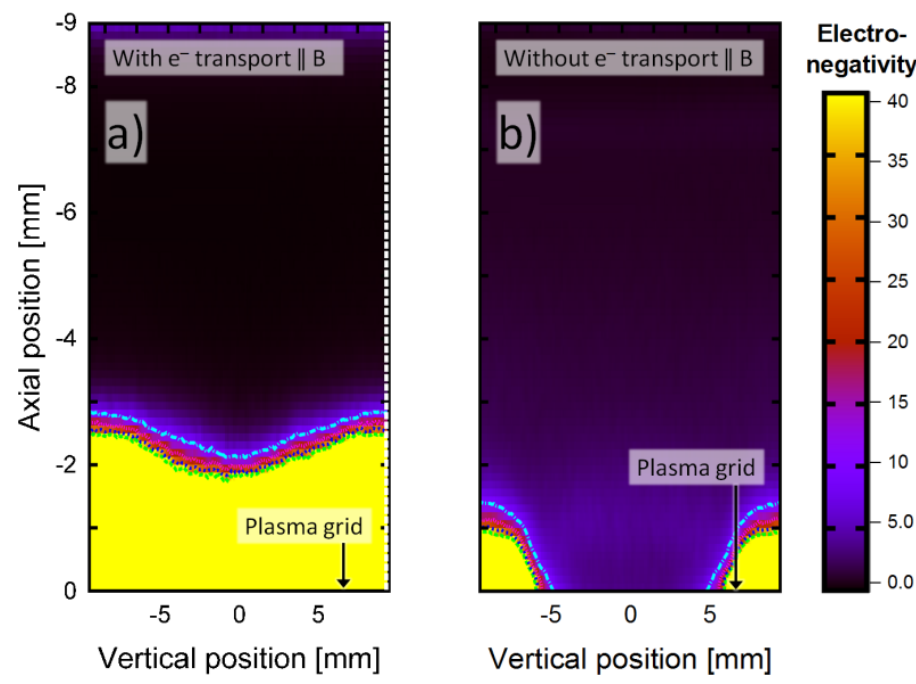

FIGURE 6. Electronegativity $\alpha$ close to the PG calculated by the 3D version of Keio-BFX [56]. a) Taking into account the transport of electrons parallel to field lines of the magnetic filter. b) Neglecting the electron transport parallel to the field lines. 
First investigations on the impact of the negative ions from the PG surface on the plasma were done using 2D codes and a reduced calculation domain. It was demonstrated, that electrons are not only pushed back, but also very effectively lost parallel to the field lines towards the side walls of the ion source. Among various physical parameters, the electron loss time parallel to the magnetic field line $\left(\tau_{\|}\right)$is one of the key parameters for this process $[101,102]$. For a sufficiently low value of $\tau_{\|}$, the electron density in the plasma is strongly reduced (by more than order of magnitude) and an ion-ion plasma forms [47,48,103,104]. The 2D version of Keio-BFX predicts an axial extent of the ion-ion plasma of several centimeters [104], being in agreement with the experimental results. In [103] additionally the influence of the PG bias potential was discussed: as known experimentally (see e.g. [87]) the positive PG bias can reduce the depth of the sheath at the PG, consequently increase the electron flux towards the PG and reduce the amount of co-extracted electrons.

Investigations on the ion-ion plasma have been continued using the $3 \mathrm{D}$ version of Keio-BFX on a reduced domain [56]. The ratio of the electron loss times parallel and perpendicular $\left(\tau_{\perp}\right)$ to the magnetic field lines used as input by this code $\left(\sqrt{\tau_{\|} / \tau_{\perp}}=0.08\right)$ is the result of a rough estimation, taking into account the magnetic mirror resulting from the permanent magnets used to generate magnetic filter in the ion source under investigation, the negative ion source for JT-60U. Figure 6 shows the calculated electronegativity $\alpha$ of the plasma for $\sqrt{\tau_{\|} / \tau_{\perp}}=0.08$ (Figure 6a) and for $\sqrt{\tau_{\|} / \tau_{\perp}}=1$ (figure 6b), the latter representing no electron loss along the field lines. The axial extension of the ion-ion plasma predicted is only about $1.5 \mathrm{~mm}$ for $\sqrt{\tau_{\|} / \tau_{\perp}}=0.08$ and when neglecting the electron losses almost no ion-ion plasma is present. The short extent of the ion-ion plasma for both cases is in disagreement with the experiment and the results obtained using the 2D version of Keio-BFX. In [56] as possible reason for the latter result the different axial extent of the calculation domain used by the code is discussed $(9 \mathrm{~mm}$ between the plasma facing PG surface and the end of the domain in the 3D case instead of $20 \mathrm{~mm}$ for 2D). The same as for KeioBFX holds also for ONIX and for Bari-Ex: only a small amount of surface produced negative ions reaches the plasma and the $\mathrm{H}^{-}$density in the plasma is much smaller than in the experiment.

Presented in [54] are 2D code results for a reduced domain and reduced electron density (scaled by a factor of 20) with negative ion densities that are in the whole calculation domain (distance to the PG: up to $2 \mathrm{~cm}$ ) comparable to the electron density. But non-realistic boundary conditions have been used (strongly negative potential at the domain edge with respect to the plasma potential), resulting in an artificial accumulation of negative ions in the domain. When reducing the potential drop, also the negative ion density strongly decreases to values by a factor of 5 to 10 smaller than $n_{e}$ [54] and thus is in disagreement with the experiment. The same group presented in [55] results of a $2.5 \mathrm{D}$ code for the whole prototype source and a much stronger scaling of the plasma density (factor 400) where even a few $\mathrm{cm}$ downstream the PG an ion-ion plasma is present, although the plasma parameters and the depth of the virtual cathode is similar to the other codes. It is not known yet if this discrepancy to the results of [54] and the other codes is caused by the heavy plasma density scaling or by physical reasons (the code of [55] is up to now the only one including the positive PG bias potential on a non-reduced calculation domain).

These results demonstrate that although current $2 \mathrm{D}, 2.5 \mathrm{D}$ and $3 \mathrm{D}$ codes are appropriate and very useful tools for calculating the electron transport through the magnetic filter, obviously most of the current codes do not correctly calculate the transport of surface produced negative ions towards the plasma. The latter seems to be correlated to the dimensionality of the code (none of the $3 \mathrm{D}$ codes predicts the correct $\mathrm{H}^{-}$density in the plasma) and implies also issues when applying the codes for investigating the negative ion transport and extraction.

\section{Extraction probability of negative ions}

Initial investigations using particle tracking codes $[105,106,107]$ demonstrated that the probability of negative ions generated at the PG to reach an extraction aperture depends on parameters like the starting energy of the ions, their initial direction, the depth of the virtual cathode and the local magnetic field strength. Although these codes are based on a set of assumptions, e.g. the electrostatic field is not the result of a self-consistent calculation but an input parameter, they gave an explanation - namely more advantageous starting angles of the negative ions and a larger negative ion conversion area - for the observed higher extracted negative ion current when chamfered aperture edges are used.

In principle, 3D PIC codes are the best tool available for determining self-consistently the extraction probability over the surface of the PG. Results of such calculations can give valuable indications, for example on how to further 
improve the PG geometry. However, the inability of current 3D codes to correctly calculate the transport of surface produced negative ions into the plasma strongly reduces the applicability of these codes.

For example, ONIX predicts a large fraction of negative ions to be extracted directly, i.e. these ions do not traverse the plasma before being accelerated by the extraction potential: the meniscus covers some part of the chamfered PG aperture edge. The major part of the extracted ions is generated at a position of the aperture edge that lies downstream the meniscus (see Figures $7 \mathrm{a}$ and $7 \mathrm{c}$ ). Only a small fraction of negative ions produced on the PG surface upstream the meniscus reaches the plasma. Although using a flat grid, the results of Bari-Ex are similar [91,59].

A first step towards improving the applicability of the 3D PIC codes for calculations on the extraction probability of negative ions may be a comparison of PIC code calculations for flat and chamfered grid geometries with the respective experimental results. Although such comparisons have been reported earlier (see e.g. [91]), these calculations are based on codes that predict a far deeper virtual cathode than the current codes. Consequently, relevant physical aspects may not have been described correctly. Comparing calculations for flat and chamfered grid geometries using the latest version of ONIX (i.e. fulfilling the rules for the time step and the grid cell size) are in preparation.

\section{Formation of the meniscus}

In order to provide a good transmission through the NBI beamline, a low divergence of the accelerated $\mathrm{H}^{-}$beam is mandatory. If a beam halo is present, the amount of particles in this halo should be as small as possible. A halo, a component of the beam with increased divergence, usually is caused by optical aberrations [108]. In [109,110] the presence of a halo in negative hydrogen ion beams was additionally explained by the presence of caesium on the downstream side of the PG and thus the generation of negative ions with a disadvantageous starting angle.

The divergence of the beam and aberrations are determined mostly by the meniscus shape of the individual beamlets [21]. Better understanding the basic physical mechanisms responsible for the formation of the meniscus in negative ion sources is essential for optimizing the operation of large negative ion sources towards application in future fusion experiments. While for positive ion extraction the meniscus can be described by simple particle tracking codes, up to now no final answer exists for the question how the meniscus for negative ion extraction looks like.

As check for the general applicability of PIC codes to this topic, in [111] it was shown that the meniscus calculated by ONIX for electropositive plasmas is identical with the result from Kobra3D. In combination with the ongoing code-to-code benchmark this result represents a successful validation of the parts of the codes responsible for determining the meniscus.

Numerous basic investigations on the meniscus formation have been done using the 2D and 3D versions of KeioBFX: shown by the 2D code was a correlation between the meniscus curvature and the existence of a halo [51]. A large amount of $\mathrm{H}^{-}$being extracted near the edge of the meniscus can result in a significant beamlet broadening [51]. The latter is an interesting result taking into account that ONIX predicts a high relevance of direct excitation, i.e. the amount of $\mathrm{H}^{-}$being extracted near the edge of the meniscus is quite large.

The fraction of beam halo increases when the beam is over-focused [52]. An attempt of benchmarking the code results against experimental results was done using the $3 \mathrm{D}$ version of the code: demonstrated was a rough agreement of the power deposited by the halo on different beamline components predicted by the code and measured values [58]. This rough agreement seems to disprove the theory of the beam halo originating at the downstream side of the PG. One possible explanation for the remaining disagreement between code result and the experiment are secondary electrons (neglected by the code) [58].

The meniscus curvature is larger in the $2 \mathrm{D}$ model than in the $3 \mathrm{D}$ version of Keio-BFX, resulting in a much larger halo [57]. The fraction of the halo compared to the whole beam predicted by the 3D model is in significantly better agreement to measurements than the $2 \mathrm{D}$ results, indicating that $3 \mathrm{D}$ models can describe better the complex threedimensional plasma structure of the extraction region.

Recent results of Keio-BFX indicate that implementing Coulomb collisions between $\mathrm{H}^{-}$and $\mathrm{H}^{+}$to the code results in a significantly improved beamlet quality, namely a reduced halo [112]. This effect is currently under investigation; most possible explanation is that the Coulomb collisions reduce the horizontal and vertical velocity components of the negative ions, similar to the effect discussed in [113]. 


\section{ONIX RESULTS FOR THE PROTOTYPE SOURCE}

The performed benchmark against general physical laws and other codes as well as the availability of a massively parallelized version of the code [63] enables the application of ONIX to the prototype source and the ELISE source, using the real geometry of the extraction systems, the real 3D magnetic field topology and without scaling of plasma parameters or physical constants. Planned are the first ever done predictive calculations of negative ion extraction and electron co-extraction. These calculations - focused on general measures for suppressing the co-extracted electrons, the isotope effect hydrogen/deuterium and the grid geometry - may have a strong impact on the development of negative hydrogen ion sources towards the application at ITER.

Shown here are results of the very first of these calculations for the prototype source, done for hydrogen. Emphasis was laid on ensuring on the one hand applicability of the code results to the experiment (e.g. avoid artificial scaling) and on the other hand ensuring numerically correct results (i.e. fulfilling the rules for stable and accurate results). Thus, a second-order projection scheme is used for projecting plasma properties to and from the computational grid. The size of the calculation domain is $14 \mathrm{~mm}$ (horizontal) $\times 14 \mathrm{~mm}$ (vertical) $\times 26.5 \mathrm{~mm}$ (axial), divided up in grid cells with $\Delta x=\Delta y=\Delta z=3.5 \cdot 10^{-5} \mathrm{~m}$. The domain includes a small volume of the plasma (axial extent: $19 \mathrm{~mm}$ ), one extraction aperture of the PG (diameter: $8 \mathrm{~mm}$ ) and the extraction system up to the EG surface (axial extent: $3.5 \mathrm{~mm}$ ). For determining the electrostatic potential, the shape of the EG aperture (diameter: $6.4 \mathrm{~mm}$ ) is taken into account. The time step is $10^{-11} \mathrm{~s}$. Negative ions are produced on the PG surface with a temperature of $0.6 \mathrm{eV}$ and extracted by an potential of $10 \mathrm{kV}$; the latter being equivalent to the highest extraction potential used in the experiment.

Stable conditions regarding the particle density profiles, the potential and the extracted currents have been reached after about $1.4 \mu$ s simulated time. In order to check the stability, the calculation was continued up to $1.9 \mu \mathrm{s}$. Calculation time was about 196 hours using 4096 cores (Intel Sandy Bridge) of the HYDRA supercomputer at the Max Planck Computing and Data Facility (MPCDF), Garching, Germany.

Figure 7a shows a $2 \mathrm{D}$ profile (in the vertical-axial plane) of the electrostatic potential $\Phi$. The two grey wedges represent a small part of the PG and the chamfered area of the PG around the simulated aperture. The zero point in axial direction is the plasma facing surface of the PG. The plasma potential is about $2.5 \mathrm{eV}$. This value agrees perfectly with the theoretically expected value from [64] for $T_{\mathrm{e}}=1 \mathrm{eV}$. The plasma the potential profile is flat; the amplitude of noise and oscillations is around $0.1 \mathrm{~V}$, emphasizing that the amount of particles per grid cell $(\approx 40)$ is sufficient in order to ensure a small numerical noise
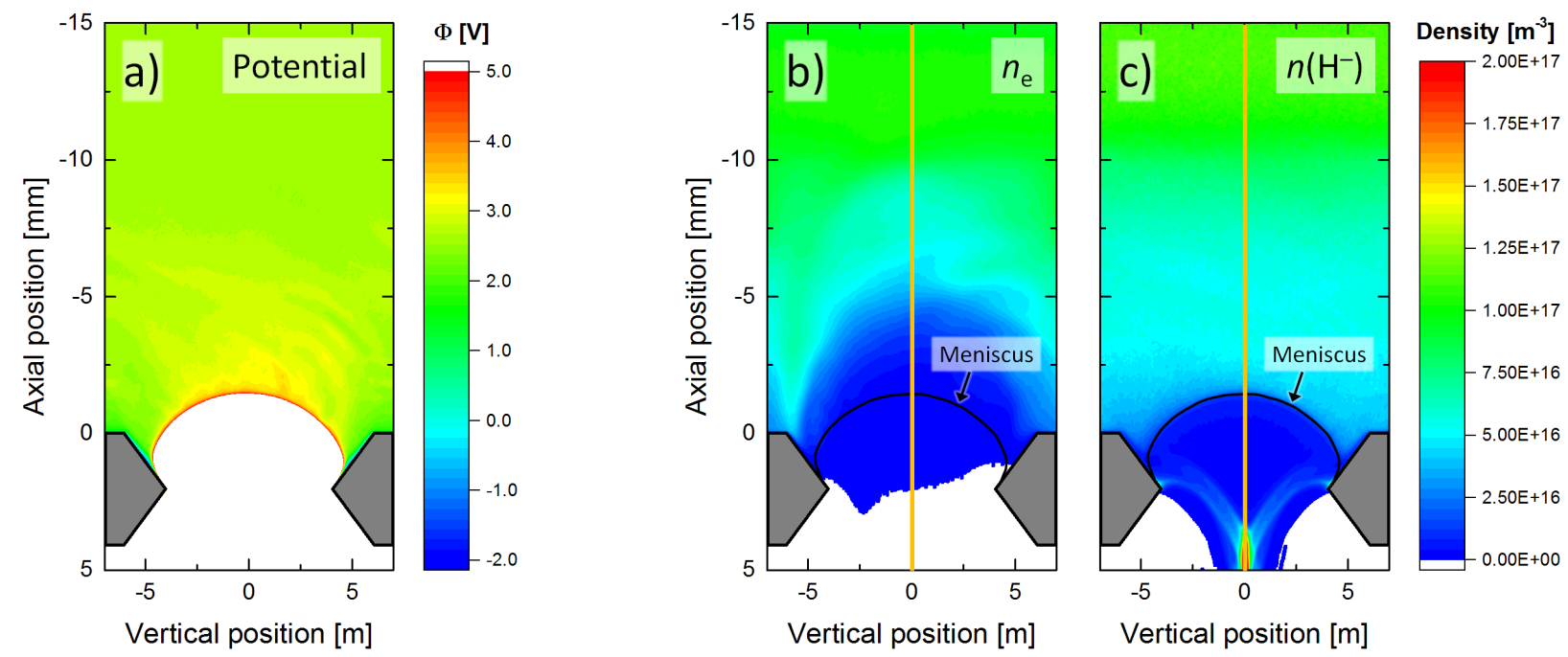

FIGURE 7. a) 2D profiles calculated using ONIX for the ITER prototype source. The grey wedges represent one chamfered aperture of the PG. a) Electrostatic potential. b) Electron density. c) Negative hydrogen ion density. Indicated in b) and c) is the meniscus.

Figure $7 \mathrm{~b}$ shows the respective 2D profile of the electron density $n_{\mathrm{e}}$. Values of up to $1.1 \cdot 10^{17} \mathrm{~m}^{-3}$ are reached. A strong drop of the electron density, representing the transition from the plasma in the (re)-injection volume to a 
strongly electronegative ion-ion plasma in the vicinity of the PG can be seen. Figure 8 shows the axial profile of the electron density, the negative ion density and the electronegativity $\alpha$ along the line indicated in orange in Figures $7 \mathrm{~b}$ and 7c. The onset of the transition to an electronegative plasma is at about $6 \mathrm{~mm}$ axial distance to the PG. Thus, the extent of the ion-ion plasma is in between the results of the 2D and 3D version of Keio-BFX.

The drop of the electron density does not occur isotropically along the vertical dimension. Volumes with almost constant electron density extend towards the flat parts of the PG left and right of the aperture. In these areas electrons follow the field lines of the deflection field generated by the permanent magnets embedded into the EG. The main component of the deflection field is perpendicular to the main component of the filter field [9], this is one reason why using $3 \mathrm{D}$ codes for a full theoretical description of the source plasma is mandatory.

Figure $7 \mathrm{c}$ shows the $2 \mathrm{D}$ profile of the negative hydrogen ion density. The highest negative ion densities $\left(\approx 10^{17} \mathrm{~m}^{-3}\right)$ occur in a very small volume close to the PG surface (barely to be seen in the figure) and are caused by the virtual cathode.

From the maximum values of the electron and negative ion densities the electron and negative ion Debye length in the plasma and close to the PG can be deduced to $2.2 \cdot 10^{-5} \mathrm{~m}$ and $1.8 \cdot 10^{-5} \mathrm{~m}$ respectively. This means that the grid cells are by $\approx 56 \%$ larger than the Debye length in the plasma and by $\approx 92 \%$ at the virtual cathode. A dedicated benchmark calculation was done using a simplified calculation domain for the used grid cell size and for $\Delta x$ smaller than $\lambda_{\mathrm{D}}$. The benchmark results for basic physical effects (sheath depth and width) are identical for the grid cell size of the present calculation, for $\Delta x<\lambda_{\mathrm{D}}$ and using analytic textbook equations. Thus, it can be stated that the stability criterion regarding the grid cell size is be fulfilled. It has to be kept in mind that using advanced projection methods increases the allowed grid cell size [41,42] and that ONIX uses a second-order projection scheme. The stability criterion regarding the time step is fulfilled: the inverse plasma frequency is around $5.3 \cdot 10^{-11} \mathrm{~s}$, by a factor of 5.3 larger than the time step.

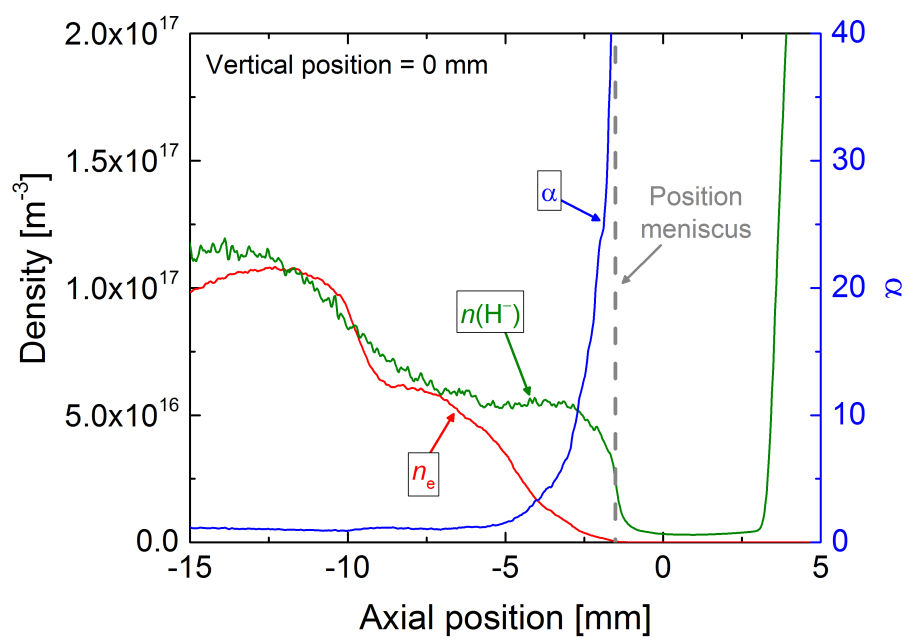

FIGURE 8. Formation of an ion-ion plasma close to the PG. Shown are the electron density, the negative ion density and the electronegativity $\alpha$ along the line indicated in orange in Figures $7 \mathrm{~b}$ and $7 \mathrm{c}$. The plasma is strongly electronegative in the last millimeters of the plasma upstream the meniscus.

The depth of the virtual cathode is about $1.1 \mathrm{eV}$ and thus in good agreement with the other 2D, 2.5D and 3D codes. Consequently, the density of negative ions transported from the PG surface into the plasma is too low and direct extraction is the most relevant production process of extracted negative hydrogen ions. In order to approximate the measured density of negative ions in the plasma coming from the $\mathrm{PG}$, additional production of $\mathrm{H}^{-}$ in the (re)-injection volume is introduced. Main aim of future calculations, however, should be to self-consistently increase the $\mathrm{H}^{-}$transport from the PG to the plasma. Although ONIX includes positive caesium ions, the simulated time is not sufficient for these slow ions to cover the distance between the (re)-injection volume and the virtual cathode. In order to include the effect of $\mathrm{Cs}^{+}$on the virtual cathode, future calculations will use a two-step procedure, calculating the density of the caesium ions using larger time steps. 
The extracted negative ion current density is about $25.3 \mathrm{~mA} / \mathrm{cm}^{2}$ and the current density of the co-extracted current density is about $11.2 \mathrm{~mA} / \mathrm{cm}^{2}$, resulting in an electron-to-ion ratio of 0.44 . These values are in very good agreement with typical results for a well caesium conditioned source.

The extracted negative ions and co-extracted electrons are treated by the same code routines as the plasma particles. Due to their high velocity the Courant-Friedrichs-Lewy condition is not fulfilled for the beamlet particles and downstream the meniscus the error bar for the particle trajectories (and thus also for the beam properties as the divergence) is high. Since the aim of the code is to investigate physical effects taking place in the plasma volume this is not an issue. Nevertheless, the beamlet particles show the expected general behavior: the electrons are deflected helically onto the EG (not to be seen in the figures) and the negative ions are almost not affected by the filter field and the deflection field. Figure $7 \mathrm{c}$ also shows that the directly extracted negative ions strongly contribute to the beamlet current; they are focused about $6.5 \mathrm{~mm}$ downstream the meniscus.

In order to improve the accuracy of the trajectories of the beamlet particles, a subcycling scheme could be implemented, following all macroparticles downstream the meniscus with significantly smaller time steps. However, for dedicated investigations on the beamlet properties coupling of the 3D PIC code results to a particle tracking code describing the beamlet is the more appropriate choice.

The strong contribution of directly extracted negative ions can have a strong impact on the divergence. Continuative investigations on this topic are a must for the future, especially with regard to the beam divergence of better than $7 \mathrm{mrad}$ required for ITER. These investigations will have to solve mainly two already mentioned issues: first, the question has to be answered why none of the existing 3D codes correctly predicts the transport of surface produced negative ions into the plasma, which can result in an overestimation of direct extraction. And second, the high fraction of direct excitation has to be proved or disproved experimentally, for example by performing a benchmark, based on measured beamlet emittances, of the calculated meniscus shape.

The present result is the first step of a parametric study. Calculations are planned for hydrogen and deuterium, based on the grid systems used in BATMAN and in ELISE, for different configurations of the magnetic filter and the deflection magnets. These calculations will be performed on the EUROfusion High Performance Computer (Marconi-Fusion) at CINECA, Bologna, Italy.

\section{SUMMARY}

Although in the last years the development of the large negative hydrogen ion sources for ITER NBI has made remarkable progress, fulfilling simultaneously all physical ITER requirements still is a challenge. Computational models, for example PIC codes, are a promising tool for identifying measures for reducing the co-extracted electron current and for improving its temporal stability, in particular in deuterium operation.

In the last years PIC codes for the extraction region of negative ion sources for fusion were applied in order to investigate individual physical aspects like the electron transport and the formation of the meniscus and a beamlet halo. The dimensionality of the codes was extended from 1D to 2D and even to 3D. However, when benchmarking code results vs. the experiment, all current codes exhibit some issues, mainly related to the transport of surface produced negative ions towards the plasma (governed by the depth of the virtual cathode).

As a first step towards solving these issues, a thorough code-to-code benchmark of some of the current $3 \mathrm{D}$ codes has been initiated. The first steps of this benchmark have been finished very successfully; now further steps into the direction of more realistic benchmark scenarios are necessary.

Coupling of 3D codes for a reduced calculation domain in close vicinity of the PG with codes predicting on a coarser mesh the plasma behavior on the scale of the whole source may be the only way for correctly describing the interplay of the three-dimensional particle drifts with the physics of the extraction region. Promising candidates for treating the whole source are fluid codes; PIC codes can only applied using scaling of physical properties.

The ONIX code is up to now the only 3D PIC code implementing the grid geometry of the test facilities for ITER NBI (the prototype source being operated at BATMAN and the ELISE source) as well as the corresponding magnetic field topology. Using massive parallelization, the code is available performing calculations for a reduced domain and the real plasma density of the ion sources without scaling physical constants. The rules for stable PIC codes are fulfilled and the code has been validated vs. basic physical laws. First results of this version of ONIX for the ITER prototype ion source are presented; these results represent the first step of predictive investigations on general measures for suppressing the co-extracted electrons and on the isotope effect hydrogen/deuterium. These investigations may have a strong impact on the development of NBI ion sources towards application at ITER and DEMO. 


\section{ACKNOWLEDGEMENTS}

The author would like to thank the authors of the different PIC codes for large negative ion sources for fusion for the good collaboration and many fruitful discussions.

The simulations presented in the last section of this work were carried out using the HYDRA supercomputer at the Max Planck Computing and Data Facility (MPCDF), Garching, Germany.

This work has been carried out within the framework of the EUROfusion Consortium and has received funding from the Euratom research and training programme 2014-2018 under grant agreement No 633053. The views and opinions expressed herein do not necessarily reflect those of the European Commission.

\section{BIBLIOGRAPHY}

[1] TAKEIRI, Y.; KANEKO, O.; TSUMORI, K.; OKA, Y.; IKEDA, K.; OSAKABE, M.; NAGAOKA, K.; ASANO, E.; KONDO, T.; SATO, M. et al. High-power and long-pulse injection with negative-ion-based neutral beam injectors in the Large Helical Device. Nucl. Fusion, 46, 2006. S199.

[2] IKEDA, Y.; UMEDA, N.; AKINO, N.; EBISAWA, N.; GRISHAM, L.; HANADA, M.; HONDA, A.; INOUE, T.; KAWAI, M.; KAZAWA, M. et al. Present status of the negative ion based NBI system for long pulse operation on JT-60U. Nucl. Fusion, 46, 2006. S211.

[3] KOJIMA, A.; HANADA, M.; TANAKA, Y.; INOUE, T.; WATANABE, K.; TANIGUCHI, M.; KASHIWAGI, M.; UMEDA, N.; TOBARI, H.; GRISHAM, L. R. Achievement and improvement of the JT-60U negative ion source for JT-60 Super Advanced (invited). Rev. Sci. Instrum., 81, 2010. 02B112.

[4] HEMSWORTH, R.; TANGA, A.; ANTONI, V. Status of the ITER neutral beam injection system (invited). Rev. Sci. Instrum., 79, 2008. 02C109.

[5] HEMSWORTH, R.; DECAMPS, H.; GRACEFFA, J.; SCHUNKE, B.; TANAKA, M.; DREMEL, M.; TANGA, A.; DE ESCH, H. P. L.; GELI, F.; MILNES, J. et al. Status of the ITER heating neutral beam system. Nucl. Fusion, 49, 2009. 045006.

[6] MASIELlO, A.; AGARICI, G.; BONICELLI, T.; SIMON, M.; ANTONI, V.; DE ESCH, H. P. L.; DE

LORENZI, A.; DREMEL, M.; FRANZEN, P.; HEMSWORTH, R. et al. European programme towards the $1 \mathrm{MeV}$ ITER NB injector. Fusion Eng. Des., 84, 2009. 1276.

[7] MASIELLO, A.; AGARICI, G.; BONICELLI, T.; FANTINI, F.; GAGLIARDI, M.; PAOLUCCI, M.; SIMON, M.; WIKUS, P.; AGOSTINETTI, P.; BIGI, M. et al. Proc. 24th IAEA Fusion Energy Conference, San Diego, USA, 2012.

[8] SPETH, E.; FALTER, H. D.; FRANZEN, P.; FANTZ, U.; BANDYOPADHYAY, M.; CHRIST, S.; ENCHEVA, A.; FRÖSCHLE, M.; HOLTUM, D.; HEINEMANN, B. et al. Overview of the RF source development programme at IPP Garching. Nucl. Fusion, 46, 2006. S220.

[9] HEINEMANN, B.; FANTZ, U.; KRAUS, W.; SCHIESKO, L.; WIMMER, C.; WÜNDERLICH, D.; BONOMO, F.; FRÖSCHLE, M.; NOCENTINI, R.; RIEDL, R. Towards large and powerful radio frequency driven negative ion sources for fusion. New J. Phys., 19, 2017. 015001.

[10] HEINEMANN, B.; FALTER, H. D.; FANTZ, U.; FRANZEN, P.; FRÖSCHLE, M.; GUTSER, R.; KRAUS, W.; NOCENTINI, R.; RIEDL, R.; SPETH, E. et al. Design of the "half-size" ITER neutral beam source for the test facility ELISE. Fusion Eng. Des., 84, 2009. 915.

[11] FRANZEN, P.; HEINEMANN, B.; FANTZ, U.; WÜNDERLICH, D.; KRAUS, W.; FRÖSCHLE, M.;

MARTENS, C.; RIEDL, R.; NOCENTINI, R.; MASIELLO, A. et al. Commissioning and first results of the ITERrelevant negative ionbeam test facility ELISE. Fusion Eng. Des., 88, 2013. 3132.

[12] SONATO, P.; AGOSTINETTI, P.; ANACLERIO, G.; ANTONI, V.; BARANA, O.; BIGI, M.; BOLDRIN, M.; CAVENAGO, M.; DAL BELLO, S.; DALLA PALMA, M. et al. The ITER full size plasma source device design. Fusion Eng. Des., 84, 2009. 269.

[13] TOIGO, V.; PIOVAN, R.; BELLO, S. D.; GAIO, E.; LUCHETTA, A.; PASQUALOTTO, R.; ZACCARIA, P.; BIGI, M.; CHITARIN, G.; MARCUZZI, D. et al. The PRIMA Test Facility: SPIDER and MITICA test-beds for ITER neutral beam injectors. New J. Phys., 19, 2017. 085004.

[14] WÜNDERLICH, D.; SCHIESKO, L.; MCNEELY, P.; FANTZ, U.; FRANZEN, P.; THE NNBI-TEAM. On the proton flux towards the plasma grid in a RF-driven negative hydrogen ion source for ITER NBI. Plasma Phys.

Control. Fusion, 54, 2012. 125002. 
[15] TAKADO, N.; HANATANI, J.; MIZUNO, T.; KATOH, K.; HATAYAMA, A.; HANADA, M.; SEKI, T.; INOUE, T. Numerical analysis of the spatial nonuniformity in a Cs-seeded $\mathrm{H}^{-}$ion source. Rev. Sci. Instrum., 77 , 2006. 03A533.

[16] BACAL, M.; WADA, M. Negative hydrogen ion production mechanisms. Appl. Phys. Rev., n. $2,2015$. 021305 .

[17] WIMMER, C.; FANTZ, U.; THE NNBI-TEAM. Cesium dynamics and $\mathrm{H}^{-}$density in the extended boundary layer of negative hydrogen ion sources for fusion. AIP Conf. Proc., 1515, 2013. 246.

[18] FRANZEN, P.; SCHIESKO, L.; FRÖSCHLE, M.; WÜNDERLICH, D.; FANTZ, U.; THE NNBI-TEAM. Magnetic Filter Field Dependence of the Performance of the RF Driven IPP Prototype Source for Negative Hydrogen Ions. Plasma Phys. Control. Fusion, 53, 2011. 115006.

[19] FRÖSCHLE, M.; FANTZ, U.; FRANZEN, P.; KRAUS, W.; NOCENTINI, R.; SCHIESKO, L.; WÜNDERLICH, D.; THE NNBI-TEAM. Magnetic filter field for ELISE - Concepts and design. Fusion Eng. Des., 88, 2013. 1015.

[20] INOUE, T.; KASHIWAGI, M.; TANIGUCHI, M.; DAIRAKU, M.; HANADA, M.; WATANABE, K.; SAKAMOTO, K. 1 MeV, ampere class accelerator R\&D for ITER. Nucl. Fusion, 46, 2006. S379.

[21] DE ESCH, H. P. L.; HEMSWORTH, R. S.; MASSMANN, P. Updated physics design ITER-SINGAP accelerator. Fusion Eng. Des., 73, 2005. 329.

[22] WHEALTON, J. H.; WHITSON, J. C. Space-Charge Ion Optics Including Extraction from a Plasma.

Part. Accel., 10, 1980. 235.

[23] FANTZ, U.; FRANZEN, P.; KRAUS, W.; SCHIESKO, L.; WIMMER, C.; WÜNDERLICH, D. Size scaling of negative hydrogen ion sources for fusion. AIP Conf. Proc., 1655, 2015.040001.

[24] FANTZ, U.; FRANZEN, P.; WÜNDERLICH, D. Development of negative hydrogen ion sources for fusion: Experiments and modelling. Chem. Phys., 398, 2012. 7.

[25] BOEUF, J. P.; CLAUSTRE, J.; CHAUDHURY, B.; FUBIANI, G. Physics of a magnetic filter for negative ion sources. II. E $\times$ B drift through the filter in a real geometry. Phys. Plasmas, 19, 2012. 113510.

[26] LISHEV, S.; SCHIESKO, L.; WÜNDERLICH, D.; FANTZ, U. Spatial distribution of the plasma parameters in the RF negative ion source prototype for fusion. AIP Conf. Proc., 1655, 2015. 040010.

[27] WÜNDERLICH, D.; FANTZ, U.; HEINEMANN, B.; KRAUS, W.; RIEDL, R.; WIMMER, C. Progress of the ELISE test facility: Towards one hour pulses in hydrogen. Nucl. Fusion, 56, 2016. 106004.

[28] WÜNDERLICH, D.; KRAUS, W.; FRÖSCHLE, M.; RIEDL, R.; FANTZ, U.; HEINEMANN, B.; THE NNBITEAM. Influence of the magnetic field topology on the performance of the large area negative hydrogen ion source test facility ELISE. Plasma Phys. Control. Fusion, 58, 2016. 125005.

[29] KRAUS, W.; WÜNDERLICH, D.; FANTZ, U.; HEINEMANN, B.; BONOMO, F.; RIEDL, R. Deuterium Results at ELISE, submitted to Rev. Sci. Instrum.

[30] BIRDSALL, C. K.; LANGDON, A. B. Plasma Physics via Computer Simulation. McGraw-Hill, New York, 1985.

[31] HOCKNEY, R. W.; EASTWOOD, J. W. Computer Simulation Using Particles. Taylor \& Francis, Bristol, 1988.

[32] TSKHAKAYA, D. The Particle-In-Cell Method. In: FEHSKE, H.; SCHNEIDER, R.; WEIßE, A.

Computational Many-Particle Physics. Springer, Heidelberg, 2008.

[33] VERBONCOEUR, J. P. Particle simulation of plasmas. Plasma Phys. Control. Fusion, 47, 2005. A231.

[34] BRACKBILL, J. U.; FORSLUND, D. W. An Implicit Method for Electromagnetic Plasma Simulation in Two Dimensions. J. Comput. Phys., 46, 1982. 271.

[35] LAPENTA, G.; BRACKBILL, J. U.; RICCI, P. Kinetic approach to microscopic-macroscopic coupling in space and laboratory plasmas. Phys. Plasmas, 13, 2006. 055904.

[36] QIN, H.; ZHANG, S.; XIAO, J.; LIU, J.; SUN, Y.; TANG, W. M. Why is Boris algorithm so good? Phys. Plasmas, 20, 2013. 084503.

[37] TAKIZUKA, T.; ABE, H. A Binary Collision Model for Plasma Simulation with a Particle Code. J. Comput. Phys., 25, 1977. 205.

[38] NANBU, K. Theory of cumulative small-angle collisions in plasmas. Physical Review E, 55, n. 4, 1997. 46424652.

[39] VAHEDI, V.; SURENDRA, M. A Monte Carlo collision model for the particle-in-cell method: applications to argon and oxygen discharges. Comput. Phys. Commun., 87, 1995. 179.

[40] KAWAMURA, W.; BIRDSALL, C. K.; VAHEDI, V. Physical and numerical methods of speeding up particle codes and paralleling as applied to RF discharges. Plasma Sources Sci. Technol., 9, 2000. 413. 
[41] OKUDA, H. Noriphysical Noises and Instabilities in Plasma Simulation due to a Spatial Grid. J. Comput. Phys., 10, 1972. 475.

[42] BIRDSALL, C. K. Particle-in-cell charged-particle simulations, plus Monte Carlo collisions with neutral atoms, PIC-MCC. IEEE Trans. Plasma Sci., 19, 1991. 65.

[43] NISHIOKA, S.; MOCHALSKYY, S.; TACCOGNA, F.; HATAYAMA, A.; FANTZ, U.; MINELLI, P. Codeto-code benchmark tests for 3D simulation models dedicated to the extraction region in negative ion sources. AIP

Conf. Proc., 1869, 2017. 050006.

[44] COURANT, R.; FRIEDRICHS, K.; LEWY, H. Über die partiellen Differenzengleichungen der

mathematischen Physik. Math. Ann., 100, 1928. 32.

[45] TACCOGNA, F.; LONGO, S.; CAPITELLI, M.; SCHNEIDER, R. Negative-Ion-Source Modeling: From Expansion to Extraction Region. IEEE Trans. Plasma Sci., 36, 2008. 1589.

[46] WÜNDERLICH, D.; GUTSER, R.; FANTZ, U. PIC code for the plasma sheath in large caesiated RF sources for negative hydrogen ions. Plasma Sources Sci. Technol., 18, 2009. 045031.

[47] SAKURABAYASHI, T.; HATAYAMA, A.; BACAL, M. Effects of a weak transverse magnetic field on negative ion transport in negative ion sources. J. Appl. Phys., 95, 2004. 3937.

[48] SAKURABAYASHI, T.; HATAYAMA, A.; BACAL, M. Effects of the weak magnetic field and electron diffusion on the spatial potential and negative ion transport in the negative ion source. Rev. Sci. Instrum., 75, 2004. 1770 .

[49] TUREK, M.; SIELANKO, J.; FRANZEN, P.; SPETH, E. Influence of transversal magnetic field on negative ion extraction process in 3D computer simulation of the multi-aperture ion source. AIP Conf. Proc., 812, 2006. 153. [50] TUREK, M.; SIELANKO, J. Simulations of negative ion extraction from a multi-aperture ion source in the presence of the magnetic filter. Vacuum, 83, 2009. S256.

[51] MIYAMOTO, K.; OKUDA, S.; HATAYAMA, A. Meniscus and beam halo formation in a tandem-type negative ion source with surface production. Appl. Phys. Lett., 100, 2012. 233507.

[52] MIYAMOTO, K.; OKUDA, S.; HATAYAMA, A.; HANADA, M.; KOJIMA, A. Study of beam optics and beam halo by integrated modeling of negative ion beams from plasma meniscus formation to beam acceleration. Appl. Phys. Lett., 102, 2013. 023512.

[53] TACCOGNA, F.; MINELLI, P. PIC modeling of negative ion sources for fusion. New J. Phys., 19, 2017. 015012.

[54] BOEUF, J. P.; FUBIANI, G.; GARRIGUES, L. Issues in the understanding of negative ion extraction for fusion. Plasma Sources Sci. Technol., 25, 2016. 045010.

[55] FUBIANI, G.; GARRIGUES, L.; HAGELAAR, G.; KOHEN, N.; BOEUF, J. P. Modeling of plasma transport and negative ion extraction in a magnetized radio-frequency plasma source. New J. Phys., 19, 2017. 015002.

[56] NISHIOKA, S.; GOTO, I.; MIYAMOTO, K.; HATAYAMA, A.; FUKANO, A. Study of ion-ion plasma formation in negative ion sources by a three-dimensional in real space and three-dimensional in velocity space particle in cell model. J. Appl. Phys., 119, 2016. 023302.

[57] NISHIOKA, S.; MIYAMOTO, K.; OKUDA, S.; GOTO, I.; HATAYAMA, A.; FUKANO, A. Study of plasma meniscus and beam halo in negative ion sources using three dimension in real space and three dimension in velocity space particle in cell model. Rev. Sci. Instrum., 85, 2014. 02A737.

[58] MIYAMOTO, K.; NISHIOKA, S.; GOTO, I.; HATAYAMA, A.; HANADA, M.; KOJIMA, A.; HIRATSUKA, J. Analysis of the beam halo in negative ion sources by using 3D3V PIC code. Rev. Sci. Instrum., 87, 2016.

$02 \mathrm{~B} 124$.

[59] TACCOGNA, F.; MINELLI, P.; CAVENAGO, M.; VELTRI, P.; IPPOLITO, N. The characterization and optimization of NIO1 ion source extraction aperture using a 3D particle-in-cell code. Rev. Sci. Instrum., 87, 2016. $02 \mathrm{~B} 145$.

[60] CAVENAGO, M.; KULEVOY, T.; PETRENKO, S.; SERIANNI, G.; ANTONI, V.; BIGI, M.; FELLIN, F.; RECCHIA, M.; VELTRI, P. Development of a versatile multiaperture negative ion source. Rev. Sci. Instrum., 83, 2012. 02A707.

[61] CAVENAGO, M.; SERIANNI, G.; MURI, M.; AGOSTINETTI, P.; ANTONI, V.; BALTADOR, C.; BARBISAN, M.; BASEGGIO, L.; BIGI, M.; CERVARO, V. et al. First experiments with the negative ion source NIO1. Rev. Sci. Instrum., 87, 2016. 02B320.

[62] MOCHALSKYY, S.; FANTZ, U.; WÜNDERLICH, D.; MINEA, T. Comparison of ONIX simulation results with experimental data from the BATMAN testbed for the study of negative ion extraction. Nucl. Fusion, 56, 2016. 106025 . 
[63] REVEL, A.; MOCHALSKYY, S.; MONTELLANO, I. M.; WÜNDERLICH, D.; FANTZ, U.; MINEA, T. Massive parallel 3D PIC simulation of negative ion extraction. J. Appl. Phys, 122, 2017. 103302.

[64] STANGEBY, P. C. Plasma sheath transmission factors for tokamak edge plasmas. Phys. Fluids, 27, 1984. 682.

[65] SELF, S. A. Exact Solution of the Collisionless Plasma-Sheath Equation. Phys. Fluids, 6, 1963. 1762.

[66] HOBBS, G. D.; WESSON, J. A. Heat flow through a Langmuir sheath in the presence of electron emission.

Plasma Phys., 9, 1967. 85.

[67] MONTELLANO, I. M. 3D-PIC Modelling of a low temperature plasma sheath with wall emission of negative particles and its application to NBI sources, in preparation.

[68] SCHWAGER, L. A. Effects of secondary and thermionic electron emission on the collector and source sheaths of a finite ion temperature plasma using kinetic theory and numerical simulation. Phys. Fluids B, 5, 1993. 631.

[69] EMMERT, G. A.; WIELAND, R. M.; MENSE, A. T.; DAVIDSON, J. N. Electric sheath and presheath in a collisionless, finite ion temperature plasma. Phys. Fluids, 23, 1980. 803.

[70] ICHIKAWA, M.; KOJIMA, A.; CHITARIN, G.; AGOSTINETTI, P.; APRILE, D.; BALTADOR, C.;

BARBISAN, M.; DELOGU, R.; HIRATSUKA, J.; MARCONATO, N. et al. Determination of the meniscus shape of a negative ion beam from an experimentally obtained beam profile. AIP Conf. Proc., 1869, 2017. 030024.

[71] KALVAS, T.; TARVAINEN, O.; ROPPONEN, T.; STECZKIEWICZ, O.; ÄRJE, J.; CLARK, H. IBSIMU: A three-dimensional simulation software for charged particle optics. Rev. Sci. Instrum., 81, 2010. $02 B 703$.

[72] SPÄDTKE, P.; MÜHLE, C. Simulation of ion extraction and beam transport. Rev. Sci. Instrum., 71, 2000. 820.

[73] LETTRY, J.; AGUGLIA, D.; ANDERSSON, P.; BERTOLO, S.; BUTTERWORTH, A.; COUTRON, Y.; DALLOCCHIO, A.; CHAUDET, E.; GIL-FLORES, J.; GUIDA, R. et al. Status and operation of the Linac4 ion source prototypes. Rev. Sci. Instrum., 85, 2014. 02B122.

[74] LETTRY, J.; AGUGLIA, D.; ALESSI, J.; ANDERSSON, P.; BERTOLO, S.; BRIEFI, S.; BUTTERWORTH, A.; COUTRON, Y.; DALLOCCHIO, A.; DAVID, N. et al. Linac4 $\mathrm{H}^{-}$ion sources. Rev. Sci. Instrum., 87, 2016. $02 \mathrm{~B} 139$.

[75] LETTRY, J. Private communication, 2017.

[76] TSUMORI, K.; WADA, M. Diagnostics tools and methods for negative ion source plasmas, a review. New J. Phys., 19, 2017. 045002.

[77] PROCASSINI, R. J.; BIRDSALL, C. K.; MORSE, E. C. A fully kinetic, self-consistent particle simulation model of the collisionless plasma-sheath region. Phys. Fluids B, 2, 1990. 3191.

[78] GOZADINOS, G.; VENDER, D.; TURNER, M. M. Boundary Conditions and Particle Loading for the Modeling of a Semi-infinite Plasma. J. Comput. Phys., 172, 2001. 348.

[79] GARRIGUES, L.; FUBIANI, G.; BOEUF, J. P. Appropriate use of the particle-in-cell method in low temperature plasmas: Application to the simulation of negative ion extraction. J. Appl. Phys., 120, 2016. 213303. [80] HAGELAAR, G. J. M.; FUBIANI, G.; BOEUF, J.-P. Model of an inductively coupled negative ion source: I. General model description. Plasma Sources Sci. Technol., 20, 2011. 015001.

[81] BOEUF, J. P.; HAGELAAR, G. J. M.; SARRAILH, P.; FUBIANI, G.; KOHEN, N. Model of an inductively coupled negative ion source: II. Application to an ITER type source. Plasma Sources Sci. Technol., 20, 2011. 015002.

[82] LISHEV, S.; SCHIESKO, L.; WÜNDERLICH, D.; FANTZ, U. Influence of the configuration of the magnetic filter field on the discharge structure in the RF driven negative ion source prototype for fusion. AIP Conf. Proc., 1869, 2017. 030042.

[83] FANTZ, U.; HOPF, C.; WÜNDERLICH, D.; FRIEDL, R.; FRÖSCHLE, M.; HEINEMANN, B.; KRAUS, W.; KURUTZ, U.; RIEDL, R.; NOCENTINI, R. et al. Towards Powerful Negative Ion Beams at the Test Facility ELISE for the ITER and DEMO NBI Systems.

[84] FANTZ, U.; FRANZEN, P.; KRAUS, W.; BERGER, M.; CHRIST-KOCH, S.; FALTER, H. D.; FRÖSCHLE, M.; GUTSER, R.; HEINEMANN, B.; MARTENS, C. et al. Physical performance analysis and progress of the development of the negative ion RF source for the ITER NBI system. Nucl. Fusion, 49, 2009. 125007.

[85] ECKSTEIN, W.; BIERSACK, J. P. Reflection of low-energy hydrogen from solids. Appl. Phys. A, 38, 1985. 123.

[86] NAKANO, H.; TSUMORI, K.; NAGAOKA, K.; SHIBUYA, M.; FANTZ, U.; KISAKI, M.; IKEDA, K.; OSAKABE, M.; KANEKO, O.; ASANO, E. et al. Cavity Ring-Down System for Density Measurement of Negative Hydrogen Ion on Negative Ion Source. AIP Conf. Proc., 1390, 2100. 359.

[87] CHRIST-KOCH, S.; FANTZ, U.; BERGER, M. Laser photodetachment on a high power, low pressure rfdriven negative hydrogen ion source. Plasma Sources Sci. Technol., 18, 2009. 025003. 
[88] TACCOGNA, F.; MINELLI, P.; LONGO, S.; CAPITELLI, M.; SCHNEIDER, R. Modeling of a negative ion source. III. Two-dimensional structure of the extraction region. Phys. Plasmas, 17, 2010. 063502.

[89] MOCHALSKYY, S.; LIFSCHITZ, A. F.; MINEA, T. Extracted current saturation in negative ion sources. J. Appl. Phys., 111, 2012. 113303.

[90] MCADAMS, R.; BACAL, M. The negative ion flux across a double sheath at the formation of a virtual cathode. Plasma Sources Sci. Technol., 19, 2010. 042001.

[91] TACCOGNA, F.; MINELLI, P.; LONGO, S. Three-dimensional structure of the extraction region of a hybrid negative ion source. Plasma Sources Sci. Technol., 22, 2013. 045019.

[92] FANTZ, U.; FALTER, H. D.; FRANZEN, P.; BANDYOPADHYAY, M.; HEINEMANN, B.; KRAUS, W.; MCNEELY, P.; RIEDL, R.; SPETH, E.; TANGA, A. et al. Diagnostics of the cesium amount in an RF negative ion source and the correlation with the extracted current density. Fusion Eng. Des., 74, 2005. 299.

[93] CHEN, F. F. Introduction to Plasma Physics. Springer, Heidelberg, 1974.

[94] SIMON, A. Ambipolar Diffusion in a Magnetic Field. Phys. Rev., 98, 1955. 317.

[95] HOLMES, A. J. T. Electron flow through transverse magnetic fields in magnetic multipole arc discharges. Rev. Sci. Instrum., 53, 1982. 1517.

[96] HAAS, F. A.; SURREY, E.; HOLMES, A. J. T. Investigation of the electron fluid equations in a hydrodynamic model of the negative ion source. Rev. Sci. Instrum., 63, 1992. 2720.

[97] HOLMES, A. J. T. A one-dimensional model of a negative ion source. Plasma Sources Sci. Technol., 5, 1996. 453.

[98] WÜNDERLICH, D.; GUTSER, R.; FANTZ, U.; THE NNBI-TEAM. Proc. XX ESCAMPIG, Novi Sad, Serbia, 2010.

[99] HUBA, J. D. NRL: Plasma Formulary. Naval Research Lab, Washington DC, 2016.

[100] BOEUF, J. P.; CHAUDHURY, B.; GARRIGUES, L. Physics of a magnetic filter for negative ion sources. I. Collisional transport across the filter in an ideal, 1D filter. Phys. Plasmas, 19, 2012. 113509.

[101] HATAYAMA, A.; NISHIOKA, S.; NISHIDA, K.; MATTEI, S.; LETTRY, J.; MIYAMOTO, K.; SHIBATA, T.; ONAI, M.; ABE, S.; FUJITA, S. et al. Present Status of Numerical Modeling of Hydrogen Negative Ion Sources, submitted to New J. Phys.

[102] MIYAMOTO, K.; OKUDA, S.; NISHIOKA, S.; HATAYAMA, A. Effect of basic physical parameters to control plasma meniscus and beam halo formation in negative ion sources. J. Appl. Phys., 114, 2013. 103302.

[103] KUPPEL, S.; MATSUSHITA, D.; HATAYAMA, A.; BACAL, M. Numerical analysis of electronegative plasma in the extraction region of negative hydrogen ion sources. J. Appl. Phys., 109, 2011. 013305.

[104] FUKUYAMA, T.; OKUDA, S.; FUKANO, A.; TSUMORI, K.; NAKANO, H.; HATAYAMA, A. Analysis of the double-ion plasma in the extraction region in hydrogen negative ion sources. AIP Conf. Proc., 1515, 2013. 74. [105] FUKUMASA, O.; NISHIDA, R. Modelling of negative ion transport in caesium-seeded volume negative ion sources. Nucl. Fusion, 46, 2006. S275.

[106] WÜNDERLICH, D.; GUTSER, R.; FANTZ, U. Influence of Magnetic Fields and Biasing on the Plasma of a RF Driven Negative Ion Source. AIP Conf. Proc., 925, 2007. 46.

[107] GUTSER, R.; WÜNDERLICH, D.; FANTZ, U.; THE NNBI-TEAM. Negative Hydrogen Ion Transport in RF-driven Ion Sources for ITER NBI. Plasma Phys. Control. Fusion, 51, 2009. 045005.

[108] BROWN, I. G. The Physics and Technology of Ion Sources. Wiley-WCH, Weinheim.

[109] HEMSWORTH, R. S.; ESCH, H. P. L.; KOVARI, M.; SVENSSON, L.; VILLECROZE, F. Status of the Development of the SINGAP Accelerator for ITER. AIP Conf. Proc., 925, 2007. 290.

[110] DE ESCH, H. P. L.; SVENSSON, L. Negative ion beam halo mitigation at the $1 \mathrm{MV}$ testbed at IRFM. Fusion Eng. Des., 86, 2011. 363.

[111] MOCHALSKYY, S.; WÜNDERLICH, D.; RUF, B.; FRANZEN, P.; FANTZ, U.; MINEA, T. 3D numerical simulations of negative hydrogen ion extraction using realistic plasma parameters, geometry of the extraction aperture and full 3D magnetic field map. Rev. Sci. Instrum., 85, 2014. 02 B301.

[112] HATAYAMA, A. Private communication, 2017.

[113] MAKINO, K.; SAKURABAYASHI, T.; HATAYAMA, A.; MIYAMOTO, K.; OGASAWARA, M. Analysis of negative ion velocity distribution at the extraction holes in a negative ion source. Rev. Sci. Instrum., 73, 2002. 1051. 